\title{
Three-dimensional modeling of grain structure evolution during welding of an aluminum alloy
}

\author{
H. L. Wei, ${ }^{a}$ J. W. Elmer ${ }^{b}$ and T. DebRoy ${ }^{a, *}$ \\ ${ }^{a}$ Department of Materials Science and Engineering, The Pennsylvania State University, \\ University Park, PA, 16802, USA. \\ ${ }^{\mathrm{b}}$ Materials Engineering Division, Lawrence Livermore National Laboratory, \\ Livermore, CA, 94550, USA
}

\begin{abstract}
The structure and properties of welded and additively manufactured alloys are affected by the microstructural evolution in the fusion zone (FZ) and heat affected zone (HAZ). The motion of the liquid pool and the interdependence of grain growth in both the solid and liquid regions are important in the evolution of the final grain structure. Previous investigations of microstructure evolution have been limited to either the HAZ or the FZ and in many cases in idealized isothermal systems. Here we report the evolution of grain structure and topology in three dimensions in both the FZ and the HAZ considering the motion of the liquid pool. Temporal and spatial distributions of temperature obtained from a well-tested heat transfer and liquid metal flow calculation are combined with Monte Carlo and topology calculations in a computationally efficient manner. The computed results are tested against independent experimental data for arc welding of an aluminum alloy. The average size of the columnar grains in the FZ and the equiaxed grains in the HAZ are shown to decrease with increasing scan speed. For a given weld, the size and aspect ratio of the columnar grains in the longitudinal and horizontal planes are shown to decrease with distance from the weld interface. It is further shown that the grain size distributions and topological class distributions in the HAZ are largely unaffected by the temporal and spatial variations of the temperature created by different welding parameters.
\end{abstract}

Keywords: Grain growth; Monte Carlo; Welding; Additive manufacturing 


\section{Introduction}

The mechanical properties of additively manufactured and fusion welded components depend critically on the evolution of microstructure during solidification of a molten pool of liquid metal [1-3]. The unique solidification pattern originates from a combination of the motion of the liquid pool, the temperature field near the solidification front and the grain structure of the adjacent solid [4-6]. Understanding the thermal history and the evolution of grain structure and topology is important because they affect the microstructure, properties and performance of fabricated components. Well tested computationally efficient models for the calculation of three dimensional (3D) temperature fields are now available $[7,8]$. However, very little work has been done to connect the transient 3D temperature field with grain growth in the fusion zone (FZ) and the adjacent heat affected zone (HAZ).

Both additive manufacturing (AM) and welding involve spatially and temporally variable heating and cooling conditions [9-12]. The evolution of microstructure in these systems can only be revealed by considering the movement of the liquid pool and the interdependence of grain growth in both the solid and liquid regions. This is because the FZ microstructure is influenced by the evolution of HAZ microstructure and both are affected by the transient three dimensional temperature field which depend on process variables $[13,14]$. At the solidification front, grains start growing epitaxially with the partially melted grains in the solid region. The subsequent growth is influenced by both the preferred crystallographic direction and the dominant local heat flow direction at the growth interface [13,14]. For face-centered cubic aluminum alloys, the preferred crystallographic directions for solidification are $\langle 100\rangle$. Therefore, the most rapid growth of partially melted, randomly oriented, poly-crystalline grains occurs when the maximum heat flow direction aligns with the $<100>$ directions. Other, misoriented, grains progress more slowly and are overtaken by faster moving grains.

Grain growth models for the HAZ have been proposed based on Monte Carlo (MC) technique using kinetic models of phase transformations [15-18]. Additionally, grain structure evolution in the FZ has been simulated by combining a two dimensional (2D) grain growth model with a 3D heat transfer and fluid flow model [5]. However, the 2D FZ model cannot take account of the impingement effects of columnar grains with various orientations 
in $3 \mathrm{D}$ space and the results are most useful in certain symmetry planes and not in the entire 3D component. Many of the applications of cellular automata and phase field models have considered either 2D calculations or 3D calculations in isothermal idealized systems to make the computationally intensive calculations tractable [19-21]. However, these simulations do not represent realistic welding or additive manufacturing conditions. In some other efforts, 3D grain growth utilized a computationally intensive cellular automaton model in the FZ, while ignoring grain growth in the HAZ which is known to affect the evolution of grain structure in the FZ [22-24]. Recent progress has also been reported for the grain structure prediction in the FZ and the HAZ during electron beam welding using a MC approach [25]. However, the temperature field and solidification parameters were obtained from a simplified model, which did not incorporate a detailed fluid-thermal consideration in the results.

The FZ grain structure affects mechanical properties and resistance to solidification cracking [13]. Both equiaxed and columnar grains form during welding and additive manufacturing and curved columnar grains have been observed in the FZ of aluminum alloys [13]. These grains are generally coarse and are characterized by anisotropic mechanical properties. In contrast, equiaxed grains that form in and around welds are usually small and are isotropic with uniform mechanical properties [26,27]. Although a large volume of experimental data have been reported about grain morphologies in the weld metal of aluminum alloys, very little work has been done to simulate the evolution of curved columnar and equiaxed grains in the FZ. Furthermore, the mechanism of formation of these grains has not been examined during welding or additive manufacturing.

Here we examine the formation and growth of curved columnar grains in the FZ and the evolution of the equiaxed grains in the HAZ in three dimensions considering their interdependence. The effects of scanning speed on the orientation, size and aspect ratio of the columnar grains are also studied. Furthermore, the grain size distribution and topological class distribution of the equiaxed grains in the HAZ are investigated under various scanning speeds using MC simulations. The numerical model can reveal the temporal evolution as well as the spatial distribution of grain morphologies and orientations and provide valuable insights in understanding the grain structure and topology during the solidification process. 
GTA welding of $1050 \mathrm{~A}$ aluminum $(99.5 \% \mathrm{Al})$ is considered as an example to examine the grain growth process to validate the calculated results with independent experimental data.

\section{Models and methodology}

\section{1. Heat transfer and fluid flow model}

A 3D heat transfer and fluid model has been used to simulate the temperature and velocity fields by solving the equations of conservation of mass, momentum and energy. The details of the governing equations, boundary conditions and the algorithm are available in our previous papers $[7,8,28,29]$ and are not repeated here. The composition of the aluminum alloy, the data used for the numerical calculation, and the welding parameters are presented in Tables 1, 2 and 3, respectively.

\section{2. Grain growth model}

\subsubsection{Assumptions}

The following assumptions are made in the model to achieve computational efficiency:

(1) The weld pool is at steady state, i.e. FZ and HAZ geometry does not change with time. For continuous linear welding, the validity of this assumption is well recognized. A major exception is spot welding and the analysis presented in this paper is not valid for spot welding. Another exception is for rapid welding using high power density when the instability of the keyhole precludes attainment of a steady state weld geometry.

(2) The grain growth direction is parallel to the maximum heat flow direction which is normal to the solidifying surface of the weld pool. Grains in the HAZ have random crystal orientations and during solidification grains in the FZ start to grow from these randomly oriented grains. Grains with crystallographic directions closest to the heat flow direction compete more favorably over other grains and dominate the grain structure very close to the weld pool boundary [13].

(3) The formations of planar, cellular or dendritic substructures inside the grains are not considered. The development of the subgrain structure does not have significant effect on the macroscopic grain structure for polycrystalline materials [13]. The propagating direction of a grain is determined by the local maximum heat flow direction [13]. 
(4) Solute redistribution and segregation during solidification are not considered because the material used was nearly pure aluminum $(99.5 \% \mathrm{Al})$.

(5) Undercooling during solidification is not considered because it is small under the conditions examined in this paper. The kinetic undercooling due to high interface velocities are unimportant at welding speeds of $\sim 10 \mathrm{~mm} / \mathrm{s}$, since the kinetic undercooling becomes important at 50 or 100 times these speeds [30,31]. Constitutional undercooling can also be neglected because the material used in this study was nearly pure aluminum. As a result, it is fair to assume that the solidification front is located on the solidus isotherm of the weld pool.

\subsubsection{Grain growth in the HAZ}

The grain structure evolution in the HAZ has been simulated using a MC technique which is based on the Potts' model [32]. The details of the application of the MC technique in modeling grain growth in the HAZ has been reported in the literature [15,16,33-36] and only the salient features pertinent to the specific problems in this paper are described here. For the initialization of the simulation, grid points are designated in the solid region with spacing similar to that of the average grain size of the starting base metal of $40 \mu \mathrm{m}$. The details of the physical scaling to the computational domain will be provided later with the discussion of the numerical scheme. These grid points are assigned a random orientation number between 1 and $q$, where $q$ is the total number of possible grain orientations in the simulation. The neighbor sites with unlike grain orientations give rise to grain boundaries whereas adjacent sites having the identical orientation number are in the same grain.

The grain boundary energy is specified by defining an interaction between nearest neighbor lattice sites. The local interaction energy $E$ is calculated by the Hamiltonian [15]:

$E=-J \sum_{j=1}^{n}\left(\delta S_{i} S_{j}-1\right)$

where $J$ is a positive constant which sets the scale of the grain boundary energy, $\delta$ is Kronecker's delta function, $S_{i}$ is the orientation at a randomly selected site $i, S_{j}$ are the orientations of its nearest neighbors, and $n$ is the total number of nearest neighbor sites. The sum is taken over all nearest neighbors. Each pair of nearest neighbors contribute $J$ to the total energy when they are of unlike orientations.

The kinetics of grain boundary migration are simulated by selecting a site randomly and 
altering its orientation to one of its nearest neighbor orientations based on the system energy variation due to the attempted orientation change. The probability of orientation change is defined as [37]:

$P=1$ for $\Delta E \leq 0$

$P=e^{-\frac{\Delta E}{k_{B} T}}$ for $\Delta E \geq 0$

where $\Delta E$ is the change in energy due to the change of orientation, $k_{B}$ is the Boltzmann constant and $T$ is the local site temperature. Any successful reorientation of a grain to orientations of nearest neighbor grains corresponds to boundary migration.

The grain growth kinetics obtained from the MC technique consider material properties and temperature-time history, which establishes a relation between the $\mathrm{MC}$ simulation time $\left(t_{M C S}\right)$ and real time. The atomistic model, the experimental data based (EDB) model and the grain boundary migration (GBM) model were proposed to relate $t_{M C S}$ and real time to address various situations [35]. GBM has been used in this paper where the expression of the MC time, $t_{M C S}$, can be described as [18]:

$t_{M C S}=\left\{\frac{1}{\mathrm{~K}_{1} \lambda}\left[\frac{4 \gamma A Z V_{m}^{2}}{N_{a}^{2} h} e^{\Delta S_{a} / R} \sum_{i}\left(\Delta t_{i} \exp \left(-\frac{Q}{R T_{i}}\right)\right)+L_{0}^{2}\right]^{\frac{1}{2}}-\frac{1}{\mathrm{~K}_{1}}\right\}^{\frac{1}{\mathrm{n}_{1}}}$

where $\lambda$ is the grid spacing, $K_{l}$ and $n_{l}$ are model constants, $\gamma$ is the grain boundary energy, $A$ is the accommodation probability, $Z$ is the average number of atoms per unit area at the grain boundary, $V_{m}$ is the atomic molar volume, $N_{a}$ is Avagadro's number, $h$ is Planck's constant, $\Delta S_{a}$ is the activation entropy, $Q$ is that activation enthalpy for grain growth, $T$ is the absolute temperature, $R$ is the gas constant, $L_{0}$ is the initial average grain size and $t$ is time. Thus, $t_{M C S}$ can be related to real time at any location where temperature is known as a function of time. Every location within the weld moves in real time but the $t_{M C S}$ values are location dependent. The value of $t_{M C S}$ depends on both the local temperature and clock time, as indicated in Eq. (4). The longer the time and the higher the temperature, the higher the value of $t_{M C S}$ which is a dimensionless quantity. The data used for grain growth calculation by MC simulation are presented in Table 4.

The choice of grid points in MC technique for updating the grain orientation number is random, which results in identical site selection probability. Grain growth occurs by a 
thermally activated diffusion process whereby grains grow faster in regions that experience stronger thermal cycles. Therefore, the probability $p$ to visit each site is calculated by considering the gradient of $t_{M C S}[38]$ :

$p=\frac{t_{M C S}}{t_{M C S M A X}}$

where $t_{M C S}$ is the computed MC simulation time at any site and $t_{M C S M A X}$ is the maximum MC simulation time in the entire calculation domain. Thus, locations with higher site probability have higher $t_{M C S}$ and are updated more frequently. This simulates the effect of local thermal conditions as calculated by the 3D heat and fluid transfer model, on grain growth in three dimensions.

\subsubsection{Grain growth in the FZ}

Columnar grains in the FZ grow epitaxially from the partially melted grains in the HAZ where grain growth also occurs with time. The columnar grains then grow along location dependent directions and speeds. The illustration of the solidifying portion of the melt pool and the $3 \mathrm{D}$ orthogonal coordinates used in the calculations is shown in Fig. 1. The incremental growth of grains for each time step modifies the local directions and velocities. The solidification direction is parallel to the local maximum temperature gradient, which is normal to the $\mathrm{S} / \mathrm{L}$ interface, on the trailing side of the molten pool. The temperature gradient $G$ at any location of the $\mathrm{S} / \mathrm{L}$ interface of the molten pool is calculated by $[5,6,39]$ :

$$
G=\|\nabla T\|=\left\|\frac{\partial T}{\partial x} i+\frac{\partial T}{\partial y} j+\frac{\partial T}{\partial z} k\right\|
$$

where $T$ is temperature and $i, j$ and $k$ are unit vectors in the welding direction, $\mathrm{x}$, width direction, $\mathrm{y}$ and the vertical depth direction, $\mathrm{z}$, respectively. The angle $\alpha$ between the scanning direction and the maximum heat flow direction that the grains follow is calculated by:

$$
\cos \alpha=\frac{-\partial T / \partial x}{G}
$$

The local solidification rate $R_{l o c}$ is the speed at the S/L interface on the trailing side of the molten pool moving at steady state, as indicated in Fig. 1. Its value is position dependent and changes from $R_{l o c}=0$ at the maximum weld width to $R_{l o c}=R_{\max }$ at the centerline on the top 
surface of the weld. The solidification rate is calculated as:

$R_{l o c}=R_{\max } \cdot \cos \alpha$

where $R_{\max }$ is the maximum solidification rate which is the same as the scanning speed. For the 1050A aluminum welds examined in this work, only columnar grains form in the FZ and equiaxed grains form in the HAZ.

The freshly solidified grains grow in size in the FZ which is simulated using the MC model. As can be observed from Eq. (5), the site selection probability is the highest near the pool boundary due to strong thermal cycle. The probability decreases with distance from the weld pool boundary because of weaker thermal cycles. Therefore, the FZ sites close to the pool boundary experience higher visiting frequencies than the sites further away.

\subsubsection{Numerical scheme}

The 3D simulations were carried out in a cubic lattice system in the present study. The computational domain included only one half of the specimen since the other half is a mirror image of the domain considered. The grids are uniformly spaced $40 \mu \mathrm{m}$, equal to the initial base metal grain size, in both $\mathrm{x}-, \mathrm{y}$ - and $\mathrm{z}$-directions for the grain growth calculations. The grids used in the heat transfer and fluid flow calculations are non-uniform and over 5 times larger in size. The temperature field obtained from the heat transfer and fluid flow model is interpolated to obtain local temperatures at each grid node of the finer grids used in the grain growth model. A grid system of $817 \times 200 \times 76$ was used for a corresponding domain size of 33 $\mathrm{mm} \times 8 \mathrm{~mm} \times 3 \mathrm{~mm}$ in the grain growth model.

\section{3. Calculation procedure}

The steps involved in the grain growth calculations are given below.

(1) The temperature and velocity fields in the molten pool are calculated using a well-tested heat transfer and fluid flow model [7,8]. The 3D temperature field is then read as the input data for the grain growth model.

(2) The calculation domain for grain growth is initialized to start the simulation process. The initial orientations of each site are represented by random integral numbers between 1 and 48.

(3) The molten pool moves one step ahead and the temperature field is updated. 
(4) The computational domain is scanned to detect the S/L interface. The corresponding local solidification directions and rates are calculated using Eqs. (6) and (8).

(5) The grains in the FZ grow epitaxially from the partial melted HAZ grains and also from the solidified FZ grains.

(6) The MC technique is applied to the grains in both the HAZ and FZ. The site selection probability is calculated using Eq. (5).

(7) Steps 3 to 6 are repeated until the calculation has been done for a predetermined welding time which corresponds to the length of the weld divided by the welding speed.

\section{Results and discussion}

\subsection{Temperature distribution, flow pattern and weld geometry}

Fig. 2 shows the calculated 3D temperature and velocity fields during GTA welding of 1050A aluminum. The liquid metal flows from the center to the periphery of the molten pool on the top surface, which is driven by the Marangoni stress that results from the spatial variation of surface tension due to local temperature variation. The reference vector is shown to indicate the magnitude of the liquid metal velocities which are of the order of $500 \mathrm{~mm} / \mathrm{s}$. These velocities indicate that heat is carried mainly by convection which is the primary mechanism of heat transfer within the molten pool.

The heat transfer and fluid flow model is validated by comparing the experimentally observed [40] and the computed transverse section geometries as shown in Fig. 3. Both the shape and dimensions of the weld computed from the 3D heat transfer and fluid flow model shown on the right hand side of Fig. 3 agree well with the experimental result shown on the left hand side of Fig. 3 [40]. This agreement indicates valid computed temperature distribution and heat flow directions, which are used in the simulation of solidification and grain structure evolution.

\subsection{Solidification direction and solidification rate}

Fig. 4 shows the calculated 3D maximum heat flow directions at the S/L interface for 15 incremental movements of the liquid pool. Locations A-E and A'-E' depict the molten pool boundary for the initial and final positions, respectively. For each increment, the local maximum heat flow directions are normal to the S/L interface. Therefore, the molten pool 
trailing boundary and the relevant local heat flow directions are continuously repeated during the welding process, which subsequently determines the propagation directions of the grains in the FZ.

Fig. 5 (a) shows the calculated solidification rate $R_{l o c}$ at the S/L interface across the FZ in the horizontal top $\mathrm{x}-\mathrm{y}$ plane. The local solidification rate increases from $0 \mathrm{~mm} / \mathrm{s}$ at location $\mathrm{A}$ to the maximum scanning speed of $4.2 \mathrm{~mm} / \mathrm{s}$ at location $\mathrm{C}$ on the pool center at the $\mathrm{S} / \mathrm{L}$ interface. The change in growth rate occurs because the angle $\alpha$ between the maximum temperature gradient and the scanning direction decreases from 90 to 0 degrees. The distribution of $R_{l o c}$ is similar in other horizontal planes. However, the variation of $R_{l o c}$ along the longitudinal planes is different. Fig. 5 (b) shows the variation of $R_{l o c}$ at the $\mathrm{S} / \mathrm{L}$ interface across the FZ in the longitudinal central x-z plane. It can be observed that $R_{l o c}$ is equal to the scanning speed on the top and bottom surfaces of the pool, with lower values in other locations. This is because the pool trailing edge near the top and bottom surfaces is approximately perpendicular to the scanning direction but is inclined in the interior portions of the plate. Other longitudinal planes with full penetration have similar distribution of $R_{l o c}$ to that shown in Fig. 5 (b).

\subsection{Distribution of MC site selection probability}

The evolution of grain structures in the HAZ as well as the grain structures in the FZ after solidification is simulated using $\mathrm{MC}$ technique. As introduced in the models and methodology section, the local site visiting frequencies are non-uniform in the computational domain due to the non-isothermal feature of the heating and cooling processes. The grain sizes are significantly affected by the characteristics of site selection probability, which simulates the temperature gradient around the molten pool. Fig. 6 shows the spatial distribution of site selection probability used in $\mathrm{MC}$ simulation for the grain structure evolution during GTA welding of 1050A aluminum. Note that the FZ which is formed after the solidification of molten pool is also taken together with the HAZ in the calculation of the site visiting frequencies. The probability is close to 1 near the pool boundary, due to higher temperatures there, and decreases with greater distance from the fusion line. This distribution basically follows the temperature contour map except that the intensity in the trailing region is enhanced due to longer exposure time during the thermal cycles. 


\subsection{Simulation of grain structure evolution}

\subsubsection{Temporal evolution of grain structure}

Once the 3D model of the weld has been completed, virtual cross sections through the weld can be taken at any angle relative to the weld coordinates to analyze grain growth conditions. One set of cross sections is shown in Fig. 7 that illustrates the simulated 3D evolution of the grain structures at time increments of $0.5,2.0$, and 4.0 seconds after the start of welding. In this figure, the trailing edge of the molten pool on the $\mathrm{x}$-axis is located at $\mathrm{x}=$ $29.0 \mathrm{~mm}$ at the starting position. As the scanning direction is along the $-\mathrm{x}$ direction, the corresponding point moves to $\mathrm{x}=26.9 \mathrm{~mm}$ after 0.5 second, $\mathrm{x}=20.6 \mathrm{~mm}$ after 2.0 seconds, and $\mathrm{x}=12.2 \mathrm{~mm}$ after 4.0 seconds of scanning time with the scanning speed of $4.2 \mathrm{~mm} / \mathrm{s}$. The calculations reproduce the molten pool shape, and clearly show the FZ and HAZ grains. During the movement of the molten pool, equiaxed grains in the HAZ continue to experience grain growth as they pass through the moving temperature gradient. Grains closest to the fusion line have the largest average size, and the size decreases with distance from the fusion line. In the meantime, solidification occurs in the FZ with the formation of columnar grains growing epitaxially from the partially melted grains in the HAZ at the fusion line. The shapes of the columnar grains that form in the FZ are consistent with those observed in aluminum and other alloys [1,40-43].

The temporal evolution of grain structures in a transverse $y-z$ plane perpendicular to the scanning direction is shown in Fig. 8 at time increments of $0,0.5,1.0$ and 1.5 seconds after the weld pool passes this plane. Time $t_{0}$ is defined as the time when the maximum width of the molten pool appears along the welding direction. At $t_{0}$ the grains in the HAZ have already started growing due to the heating that occurs ahead of the FZ. After 0.5 seconds the cross sectional area of the molten pool shrinks in this cross section as solidification takes place and the columnar grains occupy the reduced molten pool area. It can be directly observed that the local growth directions of the columnar grains are approximately perpendicular to the pool boundary at this stage. At $t_{0}+1.0$ second, the cross sectional area of the molten pool is further reduced and only a small part of the pool remains to be solidified. The equiaxed grains in the HAZ continue to grow larger than those at $t_{0}$, and at $t_{0}+1.5$ seconds, the transverse plane has completely solidified. 


\subsubsection{Spatial distribution of grain structure}

Fig. 9 shows the spatial distributions of grain structures in various longitudinal planes of the weld. It can be seen from the longitudinal x-z central plane that the columnar grains in the FZ are in elongated curved shapes. The full length of the columnar grains is seen in this cross section since the grains begin growing at the bottom of this central plane and continue to grow in this plane due to the curvature at the back side of the weld. Grain structures are significantly different in the longitudinal plane $1.3 \mathrm{~mm}$ away from the pool center. The columnar grains which grow in 3D are sectioned by a 2D plane here and only parts of the grains can be observed since these grains are growing at an angle on the off-central x-z planes. Thus, the growth direction of the columnar grains in the $3 \mathrm{D}$ solidification domain is important in the evolution of the grain structure. The aspect ratio and average size of the columnar grains are significantly reduced. Grain structures in the longitudinal planes $2.7 \mathrm{~mm}$ and $4.0 \mathrm{~mm}$ away from the pool center can only show very small cross sectional areas of the FZ columnar grains and the grain appearances in these planes can be easily confused with equiaxed grains. The spatial distributions of grain structures in various horizontal planes of the weld are shown in Fig. 10. Similar to the grain structures in the longitudinal planes, the complete curved columnar grains can be observed in the horizontal top plane and only the cross sections of the columnar grains can be seen in the interior horizontal planes below the surface.

It can be observed from Figs. 7 to 10 that the grains on the top surface and the longitudinal central plane are more columnar than the grains observed along the transverse sections. This difference originates from the orientations of the columnar grains in the 3D domain of linear welding with a moving heat source. As previously mentioned, the grain orientations depend on the local maximum temperature gradient at the $3 \mathrm{D}$ curved melt pool boundary and the shape of the melt pool. The curvature of the liquid pool and the movement of the pool results in the prominent columnar morphology of the grains in the longitudinal central and horizontal top planes.

It can be observed from Figs. 7 to 10 that the average grain size in the FZ is significantly larger than that in the HAZ. This is because the columnar grains in the FZ initially grow based on the partially melted equiaxed grains in the HAZ and they grow into elongated 
columnar shapes due to the local thermal conditions during solidification. As a result, much coarser grain structures are obtained in the FZ than in the HAZ.

The experimentally observed grain structure in the FZ has been compared with that simulated using the 3D grain growth model in Fig. 11. These simulated results demonstrate good agreement to actual weld microstructures in the entire computational domain, which includes both the FZ and the HAZ. The results demonstrate that the comprehensive numerical model is valid for simulation of solidification and grain growth process during GTA welding of $1050 \mathrm{~A}$ aluminum.

\subsubsection{Effect of scanning speed on grain structure}

It has been shown previously in this paper that the solidification directions and rates at the S/L interface are significantly affected by the molten pool geometries. In order to further study the influences of the geometrical characteristics of the molten pool on the solidification process and the final grain structures of the specimen, three different GTA welding cases with various scanning speeds are simulated using the $3 \mathrm{D}$ numerical model. The welding parameters are listed in Table 3. The 3D grain structures are shown in Fig. 12 for scanning speeds of $1.0 \mathrm{~mm}, 7.5 \mathrm{~mm}$ and $15 \mathrm{~mm}$, respectively. Note that these are all partial penetration welds due to a significantly larger plate thickness. Complete columnar grains can be observed on the top surface of the weld when the scanning speed is $1 \mathrm{~mm} / \mathrm{s}$. However, only parts of the columnar grains can be seen with the scanning speeds of $7.5 \mathrm{~mm} / \mathrm{s}$ on the top surface of the weld. When the scanning speed further increases to $15 \mathrm{~mm} / \mathrm{s}$, only the cross sections of the columnar grains are visible, and have an equiaxed appearance. Such variation can be attributed to the change of the molten pool shape whereby the trailing edge of the weld pool is inclined at an angle relative to the top $x-y$ surface of the weld. Note that only columnar grains are formed in the FZ in the simulated results. No equiaxed grains were observed in the FZ during GTA welding due to the low alloy content of 1050A aluminum, and the high temperature gradient $[44,45]$.

Columnar grains can be clearly observed in the central longitudinal plane for all three scanning speeds. The inclination angle of these columnar grains to the top horizontal plane increases with higher scanning speeds. This is because the pool becomes shallower and the shape change leads to variations of grain growth rates and directions. 


\subsection{Quantitative analysis of the grain structure}

\subsubsection{The size of columnar grains in the FZ}

Fig. 13 shows the variation of average cross sectional areas of the columnar grains in different horizontal and longitudinal planes at scanning speeds of $1.0 \mathrm{~mm} / \mathrm{s}, 7.5 \mathrm{~mm} / \mathrm{s}$ and 15 $\mathrm{mm} / \mathrm{s}$. The area of a columnar grain is referred to as its cross sectioned area in a 2D horizontal or longitudinal plane, which is different from the actual area of the grain taken on a plane normal to its growth direction. Note that experimental characterization of microstructure is usually done in selected $2 \mathrm{D}$ planes. Therefore, the simulated 3D grain structure cross sectioned by the $2 \mathrm{D}$ virtual planes is directly comparable to corresponding experimental observations. The error bars indicate the effect of the random size and orientation of the HAZ equiaxed grains on epitaxial growth of columnar grains in the FZ.

The average grain size is reduced with the increase of scanning speed due to diminished intensity of thermal cycles. Furthermore, the average grain size in horizontal planes decreases with the distance from the top surface, and in longitudinal planes they also decrease with the distance from the central longitudinal plane. Similar variation of grain orientations and sizes were observed during laser deposition of a Co-based alloy with different scanning speeds [46]. There are two reasons for these variations. First, the differences in the temperature histories in the FZ lead to non-uniform grain growth, with the largest effect being closest to the fusion line. Second, the local cross sectional areas of the columnar grains depend on the positions where the cross sectional planes are taken and the angle at which these planes cut through the grains. The cross sectional areas are larger near the top $\mathrm{x}-\mathrm{y}$ horizontal plane and the central $\mathrm{x}-\mathrm{z}$ longitudinal plane because locally the columnar grains grow parallel to these planes.

\subsubsection{The aspect ratio of columnar grains in the $\mathrm{FZ}$}

Fig. 14 shows the variation of average aspect ratio of the columnar grains in different horizontal and longitudinal planes with the scanning speeds of $1.0 \mathrm{~mm} / \mathrm{s}, 7.5 \mathrm{~mm} / \mathrm{s}$ and 15 $\mathrm{mm} / \mathrm{s}$. The aspect ratio is defined as the length divided by the width of a grain in any plane. The aspect ratio of the columnar grains in the horizontal planes decreases with the distance from the top surface, and in longitudinal planes it also decreases with the distance from the central longitudinal plane. The increase of scanning speed significantly reduces the aspect 
ratio in the horizontal planes close to the top surface, which can be visually observed from Fig. 13. However, the aspect ratio of the cross sectioned columnar grains in the longitudinal planes are not dependent on scanning speed. This is because the length and thickness of the columnar grains decrease simultaneously with scanning speed.

\subsubsection{The size of equiaxed grains in the HAZ}

Grain structures in the HAZ are affected by the heat input as well. Fig. 15 shows the variation of mean grain sizes with distances from the fusion line on the top surface and longitudinal central plane. The maximum mean grain sizes are observed close to the fusion line in all cases. The mean grain sizes decrease with greater distance from the fusion line, which is due to the variation of local thermal cycles. The mean grain sizes decrease with higher scanning speed which corresponds to lower heat input. These results demonstrate that grain growth in the HAZ is significantly affected by the heat input and finer grain structures in the HAZ can be obtained using lower heat input.

\subsubsection{Grain size distribution in the HAZ}

The grain size distributions in the HAZ on the top surface and longitudinal central plane for various scanning speeds are shown in Fig. 16. It can be observed from both Figs. 16 (a) and (b) that the grain size distributions are all similar despite the different heat inputs and local positions where the measurements are made. The peak frequencies are about 0.25 and the distribution of $\mathrm{R} / \mathrm{R}_{\mathrm{avg}}$ fall in the range between 0.2 and 2.25 , which demonstrates that the normalized grain size distributions are independent of the spatial distribution and temporal evolution of the temperature in the HAZ. The reason for this is that any thermal cycles in the HAZ can be visualized as a collection of numerous discreet isothermal steps so that the grain growth under different thermal cycles behaves in a similar manner as that under different isothermal conditions for different times [17].

\subsubsection{Topological properties of grains in the HAZ}

Fig. 17 shows the topological class distributions in the HAZ for various scanning speeds on the top surface and longitudinal central plane. Grains with six edges have highest frequencies and the distributions are asymmetric for all cases. The average edges per grain are approximately equal to six, which is consistent with the general topological rule [33]. The average number of sides of grains in a domain is equal to six and grains with less than six 
sides tend to shrink and those with more than six sides tend to grow. This is because grain boundary migration occurs if all the grains in a structure are not six sided. The overall result of grain growth is reducing the number of grains, thereby increasing the mean grain size and reducing the total grain boundary energy. The results in both Figs. 17 (a) and (b) show similar topological features of grains in isothermal systems, which indicates that the topological class distributions in the HAZ are unaffected by the pronounced spatial and temporal variations of the temperature.

\subsection{Discussion of the capabilities of the model}

It is interesting to point out that observations of grain structure from $2 \mathrm{D}$ cross sections can be misleading since the appearances of equiaxed grains are often sections of columnar grains made at angles nonparallel to their growth direction. For example, numerous grains in the transverse plane of the FZ shown in Fig. 8 had the appearance of equiaxed grains, although it was demonstrated in Fig. 7 that actually they were all columnar grains. Furthermore, the apparent equiaxed grains on the top surface with scanning speed of $15 \mathrm{~mm} / \mathrm{s}$ were shown in Fig. 12, which were actually columnar grains observed from the longitudinal central plane. This indicates that the observation of grain structures from the horizontal planes can also be misleading, similar to that observed in the transverse planes in Fig. 8.

The significantly different appearances of columnar grains in the FZ in various cross sections indicate that thorough examinations of grain structures in multiple serial sections in orthogonal planes are necessary to accurately reveal the overall microstructural features of the specimen. However, such experimental characterization work can be cumbersome, time consuming or even impractical in certain occasions. On the other hand, 3D numerical simulations of grain growth can provide valuable insights in understanding the evolution of grain structures during the solidification process. The model proposed in this work can provide virtual cross sections of computed 3D microstructures and reveal detailed grain structure and topology in a computationally efficient manner.

\section{Conclusions}

The evolution of grain structure and topology in an aluminum alloy weld in both the FZ and the HAZ have been examined in three dimensions considering the motion of the liquid 
pool, its shape and the size and flow of liquid within the pool. The interdependence of the FZ and HAZ grain evolution is demonstrated, along with analysis showing the local solidification conditions of each grain within the FZ. The model calculates grain size and shape for the entire weld region along any arbitrary virtual cross section. The following are the main conclusions:

(1) Higher scanning speeds increased the inclination angle of the columnar grains in the FZ to the horizontal plane, and reduced the average grain size in the FZ as expected. These trends are consistent with the experimentally observed grain structures.

(2) The computed results show that the average grain size in the FZ is significantly larger than those in the HAZ because the columnar grains in the FZ initially grow from the partially melted equiaxed grains in the HAZ, and are elongated into columnar shapes due to the local thermal conditions during solidification. The size of the equiaxed grains in the HAZ decreases with distance from the fusion line, and it further decreases with scanning speed because of the diminished intensity of thermal cycles.

(3) The aspect ratio of columnar grain cross sections in the longitudinal and horizontal planes decreased with the distance from the center and top of the weld, respectively. However, the aspect ratio was not significantly affected by the scanning speed.

(4) The grain size distributions and topological class distributions in the HAZ obeyed the normal distribution similar to isothermal systems, and were unaffected by the temporal and spatial variations of the temperature for a wide range of heat inputs.

\section{Acknowledgements:}

We acknowledge the support from US Department of Energy NEUP Grant DE-NE0008280. 


\section{References:}

[1] S. Kou, Y. Le. Welding parameters and the grain-structure of weld metal - a thermodynamic consideration, Metall. Trans. A 19 (1988) 1075-1082.

[2] S.A. David, J.M. Vitek. Correlation between solidification parameters and weld microstructures, Int. Mater. Rev. 34 (1989) 213-245.

[3] W.J. Sames, F.A. List, S. Pannala, R.R. Dehoff, S.S. Babu. The metallurgy and processing science of metal additive manufacturing, Int. Mater. Rev. 61 (2016) 315-360.

[4] G.P. Dinda, A.K. Dasgupta, J. Mazumder. Texture control during laser deposition of nickel-based superalloy, Scripta Mater. 67 (2012) 503-506.

[5] H.L. Wei, J.W. Elmer, T. DebRoy. Origin of grain orientation during solidification of an aluminum alloy, Acta Mater. 115 (2016) 123-131.

[6] H.L. Wei, J. Mazumder, T. DebRoy. Evolution of solidification texture during additive manufacturing, Sci. Rep. 5 (2015) Article number: 16446.

[7] K. Mundra, T. DebRoy, K.M. Kelkar. Numerical prediction of fluid flow and heat transfer in welding with a moving heat source, Numer. Heat Tr. A-appl 29 (1996) 115-129.

[8] S. Mishra, T. DebRoy. A heat-transfer and fluid-flow-based model to obtain a specific weld geometry using various combinations of welding variables, J. Appl. Phys. 98 (2005) Article Number: 044902.

[9] V. Manvatkar, A. De, T. DebRoy. Heat transfer and material flow during laser assisted multi-layer additive manufacturing, J. Appl. Phys. 116 (2014) Article number: 124905.

[10] V. Manvatkar, A. De, T. DebRoy. Spatial variation of melt pool geometry, peak temperature and solidification parameters during laser assisted additive manufacturing process, Mater. Sci. Tech. 31 (2015) 924-930.

[11] T. Mukherjee, J.S. Zuback, A. De, T. DebRoy. Printability of alloys for additive manufacturing, Sci. Rep. 6 (2016) Article number: 19717.

[12] T. Debroy, S.A. David. Physical processes in fusion welding, Rev. Mod. Phys. 67 (1995) 85-112.

[13] S. Kou. Welding metallurgy. 2nd ed., John Wiley \& Sons, Hoboken, NJ, 2003.

[14] S.A. David, T. Debroy. Current issues and problems in welding science, Science 257 (1992) 497-502. 
[15] S. Sista, Z. Yang, T. Debroy. Three-dimensional Monte Carlo simulation of grain growth in the heat-affected zone of a $2.25 \mathrm{Cr}-1 \mathrm{Mo}$ steel weld, Metall. Mater. Trans. B 31 (2000) 529-536.

[16] Z. Yang, S. Sista, J.W. Elmer, T. Debroy. Three dimensional Monte Carlo simulation of grain growth during GTA welding of titanium, Acta Mater. 48 (2000) 4813-4825.

[17] S. Mishra, T. DebRoy. Measurements and Monte Carlo simulation of grain growth in the heat-affected zone of Ti-6Al-4V welds, Acta Mater. 52 (2004) 1183-1192.

[18] S. Mishra, T. DebRoy. Non-isothermal grain growth in metals and alloys, Mater. Sci. Tech. 22 (2006) 253-278.

[19] M. Rappaz, C.A. Gandin. Probabilistic modeling of microstructure formation in solidification processes, Acta Metallurgica Et Materialia 41 (1993) 345-360.

[20] M. Asta, C. Beckermann, A. Karma, W. Kurz, R. Napolitano, M. Plapp, G. Purdy, M. Rappaz, R. Trivedi. Solidification microstructures and solid-state parallels: Recent developments, future directions, Acta Mater. 57 (2009) 941-971.

[21] L.-Q. Chen. Phase-Field models For microstructure evolution, Ann. Rev. Mater. Res. 32 (2002) 113-140.

[22] S. Chen, G. Guillemot, C.-A. Gandin. 3D Coupled Cellular Automaton (CA)-Finite Element (FE) Modeling for Solidification Grain Structures in Gas Tungsten Arc Welding (GTAW), ISIJ Int. 54 (2014) 401-407.

[23] S. Chen, G. Guillemot, C.-A. Gandin. Three-dimensional cellular automaton-finite element modeling of solidification grain structures for arc-welding processes, Acta Mater. 115 (2016) 448-467.

[24] W.D. Tan, Y.C. Shin. Multi-scale modeling of solidification and microstructure development in laser keyhole welding process for austenitic stainless steel, Comp. Mater. Sci. 98 (2015) 446-458.

[25] T.M. Rodgers, J.D. Madison, V. Tikare, M.C. Maguire. Predicting Mesoscale Microstructural Evolution in Electron Beam Welding, JOM 68 (2016) 1419-1426.

[26] H.B. Dong, P.D. Lee. Simulation of the columnar-to-equiaxed transition in directionally solidified Al-Cu alloys, Acta Mater. 53 (2005) 659-668. 
[27] L. Beltran-Sanchez, D.M. Stefanescu. A quantitative dendrite growth model and analysis of stability concepts, Metall. Mater. Trans. A 35A (2004) 2471-2485.

[28] A. De, T. DebRoy. Probing unknown welding parameters from convective heat transfer calculation and multivariable optimization, J. Phys. D. Appl. Phys. 37 (2004) 140-150.

[29] H.L. Wei, J.J. Blecher, T.A. Palmer, T. Debroy. Fusion zone microstructure and geometry in complete-joint-penetration laser-arc hybrid welding of low-alloy steel, Weld. J. 94 (2015) 135S-144S.

[30] M.J. Aziz, T. Kaplan. Continuous growth-model for interface motion during alloy solidification, Acta Metall. 36 (1988) 2335-2347.

[31] P.M. Smith, M.J. Aziz. Solute trapping in aluminum alloys, Acta Metallurgica Et Materialia 42 (1994) 3515-3525.

[32] R.B. Potts. Some generalized order-disorder transformations, Proceedings of the Cambridge Philosophical Society 48 (1952) 106-109.

[33] S. Mishra, T. DebRoy. Grain topology in Ti-6Al-4V welds-Monte Carlo simulation and experiments, J. Phys. D. Appl. Phys. 37 (2004) 2191-2196.

[34] Z. Yang, J.W. Elmer, J. Wong, T. Debroy. Evolution of titanium arc weldment macro and microstructures - Modeling and real time mapping of phases, Weld. J. 79 (2000) 97S-112S.

[35] J.H. Gao, R.G. Thompson. Real time-temperature models for Monte Carlo simulations of normal grain growth, Acta Mater. 44 (1996) 4565-4570.

[36] B. Radhakrishnan, T. Zacharia. Simulation of curvature-driven grain growth by using a modified Monte Carlo algorithm, Metall. Mater. Trans. A 26 (1995) 167-180.

[37] M.P. Anderson, D.J. Srolovitz, G.S. Grest, P.S. Sahni. Computer simulation of grain growth - I. Kinetics, Acta Metall. 32 (1984) 783-791.

[38] B. Radhakrishnan, T. Zacharia. Monte Carlo simulation of grain boundary pinning in the weld heat-affected zone, Metall. Mater. Trans. A 26 (1995) 2123-2130.

[39] J.J. Blecher, T.A. Palmer, T. DebRoy. Solidification Map of a Nickel-Base Alloy, Metall. Mater. Trans. A 45A (2014) 2142-2151. 
[40] P. Schempp, M. Rethmeier. Understanding grain refinement in aluminium welding Henry Granjon Prize 2015 winner category B: materials behaviour and weldability, Weld. World. 59 (2015) 767-784.

[41] Y. Arata, F. Matsuda, S. Mukae, M. Katoh. Effect of weld soldificaiton mode on tensile properties of aluminum weld metal, Transactions of JWRI 2 (1973) 184-190.

[42] S. Kou, Y. Le. Grain-structure and solidification cracking in oscillated arc welds of 5052 aluminum-alloy, Metall. Trans. A 16 (1985) 1345-1352.

[43] P. Schempp, C.E. Cross, A. Pittner, G. Oder, R.S. Neumann, H. Rooch, I. Dorfel, W. Osterle, M. Rethmeier. Solidification of GTA Aluminum Weld Metal: Part 1-Grain Morphology Dependent upon Alloy Composition and Grain Refiner Content, Weld. J. 93 (2014) 53S-59S.

[44] P. Schempp, C.E. Cross, A. Pittner, M. Rethmeier. Influence of Solute Content and Solidification Parameters on Grain Refinement of Aluminum Weld Metal, Metall. Mater. Trans. A 44A (2013) 3198-3210.

[45] W.F. Savage. Solidification, segregation and weld imperfection, Weld. World. 18 (1980) 89-113.

[46] V. Ocelík, I. Furár, J.T.M. De Hosson. Microstructure and properties of laser clad coatings studied by orientation imaging microscopy, Acta Mater. 58 (2010) 6763-6772. 
Table 1 Chemical compositions of 1050A aluminum (wt. \%) [40].

\begin{tabular}{ccccccccccccr}
\hline $\mathrm{Mg}$ & $\mathrm{Si}$ & $\mathrm{Fe}$ & $\mathrm{Mn}$ & $\mathrm{Cr}$ & $\mathrm{Ti}$ & $\mathrm{Ni}$ & $\mathrm{Cu}$ & $\mathrm{Zn}$ & $\mathrm{B}$ & $\mathrm{V}$ & $\mathrm{Zr}$ & $\mathrm{Al}$ \\
\hline 0.001 & 0.09 & 0.24 & 0.004 & 0.001 & 0.008 & 0.004 & 0.01 & 0.01 & 0.0003 & 0.01 & 0.001 & Bal. \\
\hline
\end{tabular}

Table 2 Data used for the calculation and temperature and velocity fields.

\begin{tabular}{|c|c|}
\hline Variables & Value \\
\hline Arc radius $(\mathrm{mm})$ & 1.8 \\
\hline Arc energy efficiency & 0.75 \\
\hline Solidus temperature $(\mathrm{K})$ & 917 \\
\hline Liquidus temperature $(\mathrm{K})$ & 930 \\
\hline Density of metal $\left(\mathrm{kg} \mathrm{m}^{-3}\right)$ & 2700 \\
\hline Thermal conductivity of solid $\left(\mathrm{W} \mathrm{m}^{-1} \mathrm{~K}^{-1}\right)$ & 211 \\
\hline Effective thermal conductivity of liquid ( $\mathrm{W} \mathrm{m}^{-1} \mathrm{~K}^{-1}$ ) & 126 \\
\hline Effective viscosity of liquid $\left(\mathrm{kg} \mathrm{m}^{-1} \mathrm{~s}^{-1}\right)$ & 0.01 \\
\hline Temperature coefficient of surface tension $\left(\mathrm{N} \mathrm{m}^{-1} \mathrm{~K}^{-1}\right)$ & -0.35 \\
\hline Specific heat of solid $\left(\mathrm{J} \mathrm{kg}^{-1} \mathrm{~K}^{-1}\right)$ & 0.90 \\
\hline Specific heat of liquid $\left(\mathrm{J} \mathrm{kg}^{-1} \mathrm{~K}^{-1}\right)$ & 1.18 \\
\hline Coefficient of thermal expansion $\left(\mathrm{K}^{-1}\right)$ & $2.30 \times 10^{-5}$ \\
\hline
\end{tabular}

Table 3 GTA welding process parameters [40].

\begin{tabular}{ccccc}
\hline Weld No. & Scanning speed $(\mathrm{mm} / \mathrm{s})$ & Current $(\mathrm{A})$ & Voltage $(\mathrm{V})$ & Plate thickness $(\mathrm{mm})$ \\
\hline 1 & 4.2 & 175 & 11.2 & 3 \\
2 & 1.0 & 196 & 11.7 & 25 \\
3 & 7.5 & 196 & 11.7 & 25 \\
4 & 15.0 & 196 & 11.7 & 25 \\
\hline
\end{tabular}


Table 4 Data used for grain growth calculation by MC simulation [18].

\begin{tabular}{ll}
\hline Variables & Value \\
\hline Initial grid spacing $(\mu \mathrm{m}), L_{0}$ & 40 \\
Grain boundary energy $\left(\mathrm{J} \mathrm{m}^{-2}\right), \gamma$ & 0.324 \\
Accommodation probability, $A$ & 1.0 \\
Average number per unit area at grain boundary (atoms $\left.\mathrm{m}^{-2}\right), Z$ & $1.1 \times 10^{19}$ \\
Activation enthalpy for grain growth $\left(\mathrm{J} \mathrm{mol}^{-1}\right), Q$ & $1.42 \times 10^{5}$ \\
Atomic molar volume $\left(\mathrm{m}^{3} \mathrm{~mol}^{-1}\right), V_{m}$ & $1.0 \times 10^{-5}$ \\
Avagadro's number $\left(\mathrm{mol}^{-1}\right), N_{a}$ & $6.02 \times 10^{23}$ \\
Planck's constant $\left(\mathrm{J} \mathrm{s}^{2}, h\right.$ & $6.624 \times 10^{-34}$ \\
Activation entropy $\left(\mathrm{J} \mathrm{mol}^{-1} \mathrm{~K}^{-1}\right), \Delta S_{a}$ & 5.9 \\
Gas constant $\left(\mathrm{J} \mathrm{K}^{-1} \mathrm{~mol}^{-1}\right), R$ & 8.314 \\
\hline
\end{tabular}




\section{Figure Captions:}

Fig. 1. Illustration of the $3 \mathrm{D}$ orthogonal coordinates used in the calculations. $R_{\max }$ is the maximum solidification rate which is equal the scanning speed, $R_{l o c}$ is the local solidification rate and $\alpha$ is the angle between the scanning direction and the local maximum heat flow direction.

Fig. 2. Computed temperature and velocity fields during GTA welding of 1050A aluminum, where the molten pool moves in the $-\mathrm{x}$ direction. Welding current: $175 \mathrm{~A}$, voltage: $11.2 \mathrm{~V}$, scanning speed: $4.2 \mathrm{~mm} / \mathrm{s}$.

Fig. 3. Comparison of the experimentally determined FZ geometry with that computed using the heat transfer and fluid flow model for GTA welding of 1050A aluminum. The experimentally observed cross section [40] is shown on the left. The calculated temperature and velocity fields are shown on the right.

Fig. 4. Calculated 3D maximum heat flow directions at the S/L interface with 15 molten pool moving increments. 1-2-3 and 4-5-6 indicate the pool trailing edge of the first and last steps.

Fig. 5. Calculated solidification rate $R_{l o c}$ at the $\mathrm{S} / \mathrm{L}$ interface across the FZ of GTA weld with scanning speed of $4.2 \mathrm{~mm} / \mathrm{s}$. (a) Horizontal top $\mathrm{x}-\mathrm{y}$ plane. (b) Longitudinal central x-z plane. A-B-C-D-E indicates different locations on the trailing edge of the molten pool.

Fig. 6. Spatial distribution of MC site selection probability in the horizontal top and longitudinal central planes.

Fig. 7. Temporal evolution of the grain structures in the horizontal top and longitudinal central planes during GTA welding of 1050A aluminum after different times.

Fig. 8. Temporal evolution of grain structures in a transverse plane during GTA welding of 1050A aluminum after different times. The dash curves indicate the fusion lines of the weld.

Fig. 9. Spatial distribution of grain structures in various longitudinal planes of the weld.

Fig. 10. Spatial distribution of grain structures in various horizontal planes of the weld.

Fig. 11. Comparison of the experimentally observed grains structure in the FZ [40] with that simulated using the 3D grain growth model for GTA welding of 1050A aluminum.

Fig. 12. Comparison of simulated grain structures for partial penetration GTA welding of 1050A aluminum with scanning speeds of $1 \mathrm{~mm} / \mathrm{s}, 7.5 \mathrm{~mm} / \mathrm{s}$ and $15 \mathrm{~mm} / \mathrm{s}$, respectively.

Fig. 13. Comparison of the average grain areas in the FZ in various planes of the simulated grain structures with scanning speeds of $1 \mathrm{~mm} / \mathrm{s}, 7.5 \mathrm{~mm} / \mathrm{s}$ and $15 \mathrm{~mm} / \mathrm{s}$, respectively. (a) Horizontal x-y 
planes. (b) Longitudinal x-z planes.

Fig. 14. Comparison of the average aspect ratio in the FZ in various planes of the simulated grain structures with scanning speeds of $1 \mathrm{~mm} / \mathrm{s}, 7.5 \mathrm{~mm} / \mathrm{s}$ and $15 \mathrm{~mm} / \mathrm{s}$, respectively. (a) Horizontal x-y planes. (b) Longitudinal x-z planes.

Fig. 15. Average grain size in the HAZ for various scanning speeds. (a) Top surface. (b) Longitudinal central plane.

Fig. 16. Grain size distributions in the HAZ for various scanning speeds. (a) $1 \mathrm{~mm}$ from the fusion line on the top surface. (b) $1 \mathrm{~mm}$ from the fusion line on the longitudinal central plane.

Fig. 17. Topological class distributions in the HAZ for various scanning speeds. (a) $1 \mathrm{~mm}$ from the fusion line on the top surface. (b) $1 \mathrm{~mm}$ from the fusion line on the longitudinal central plane. 


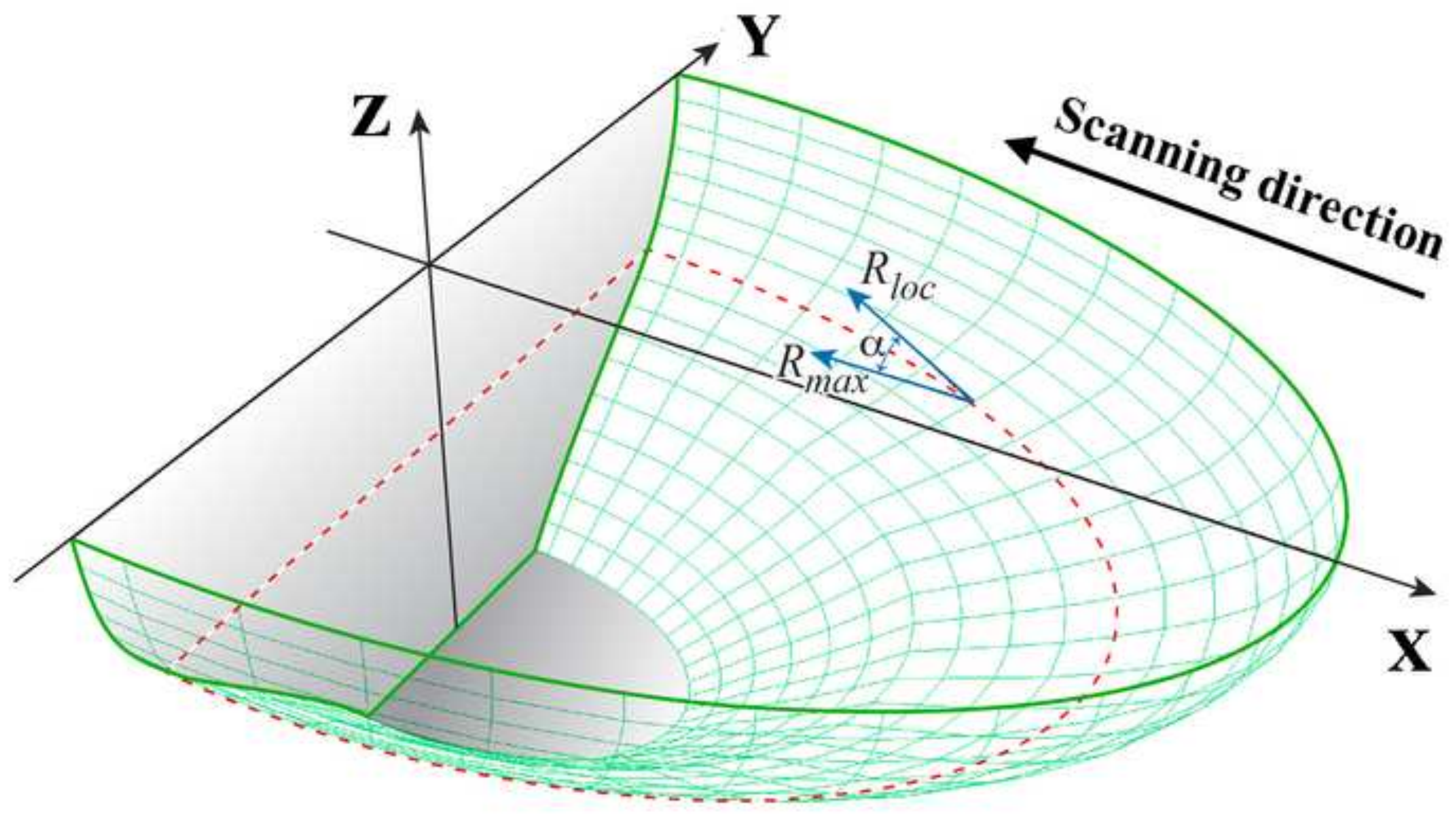




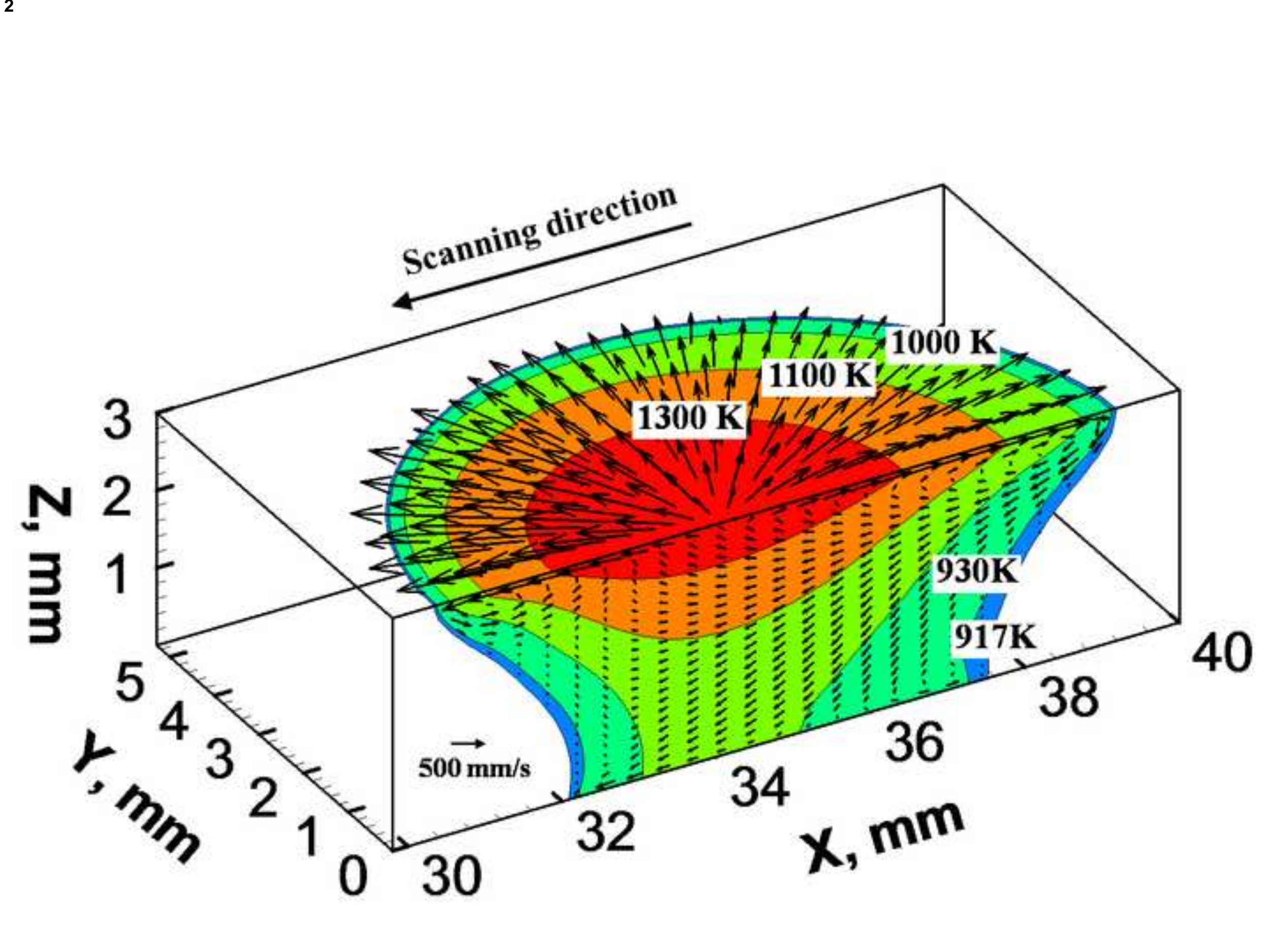




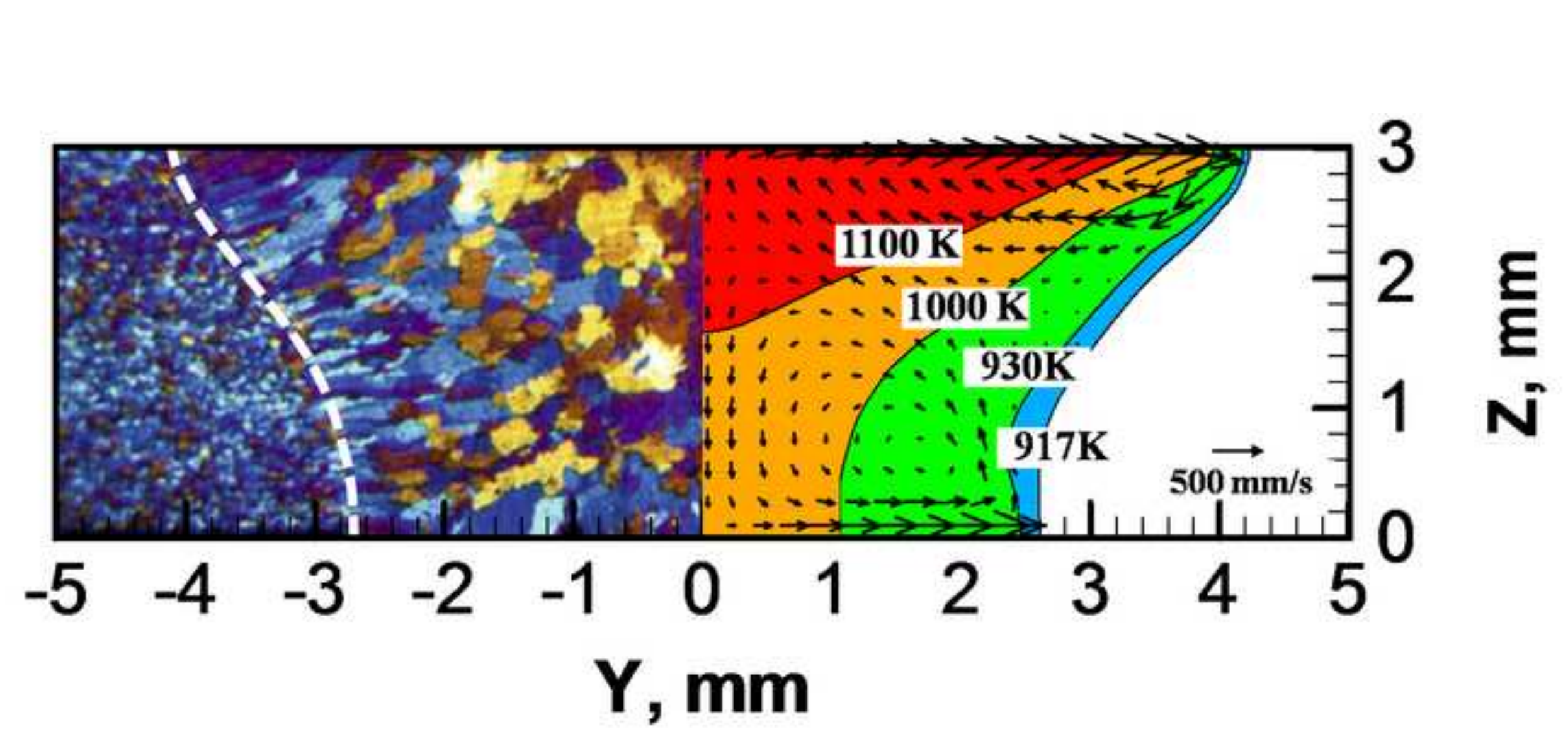

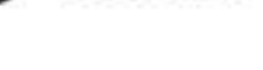

\author{
$\mathrm{mm}$
}




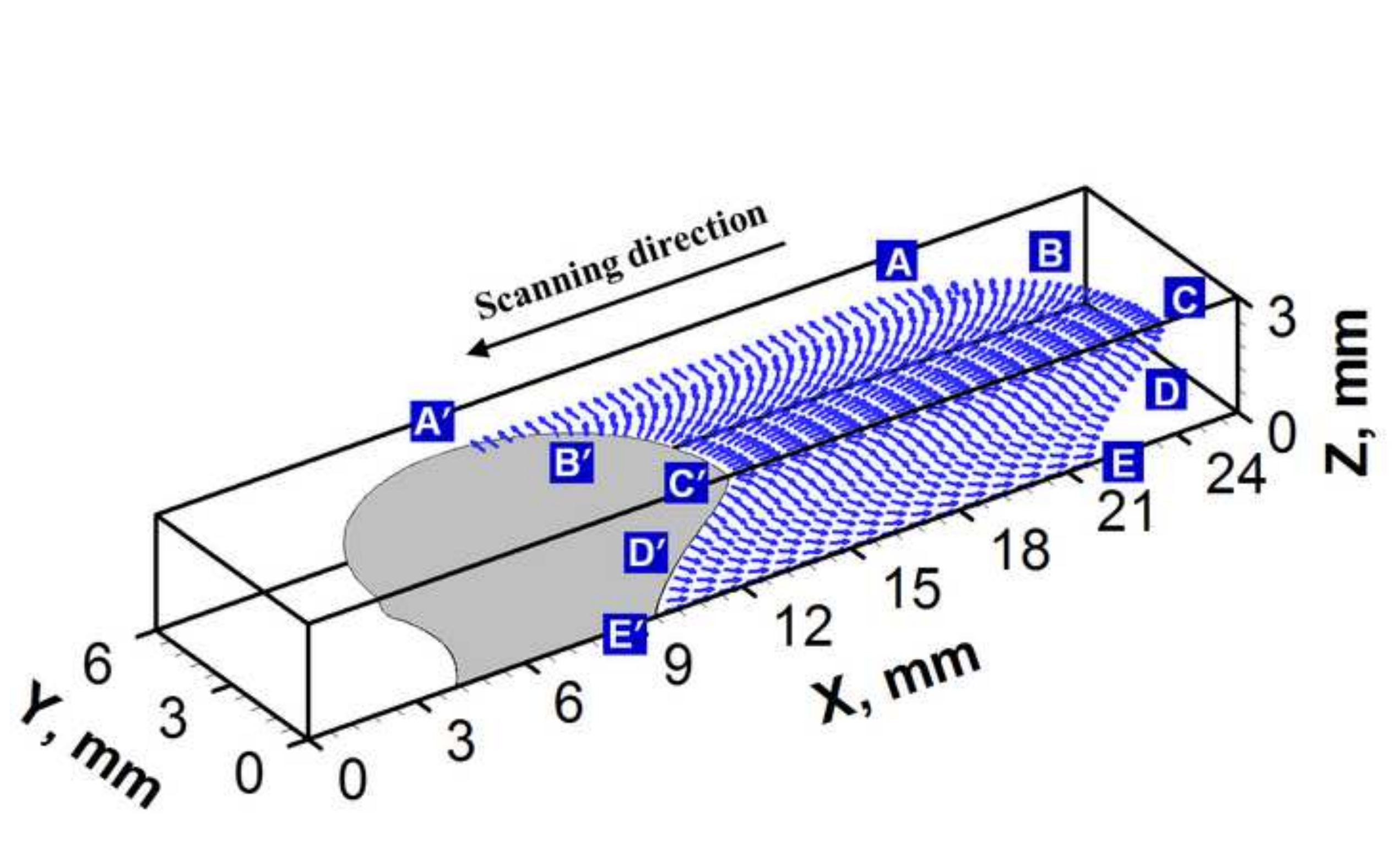



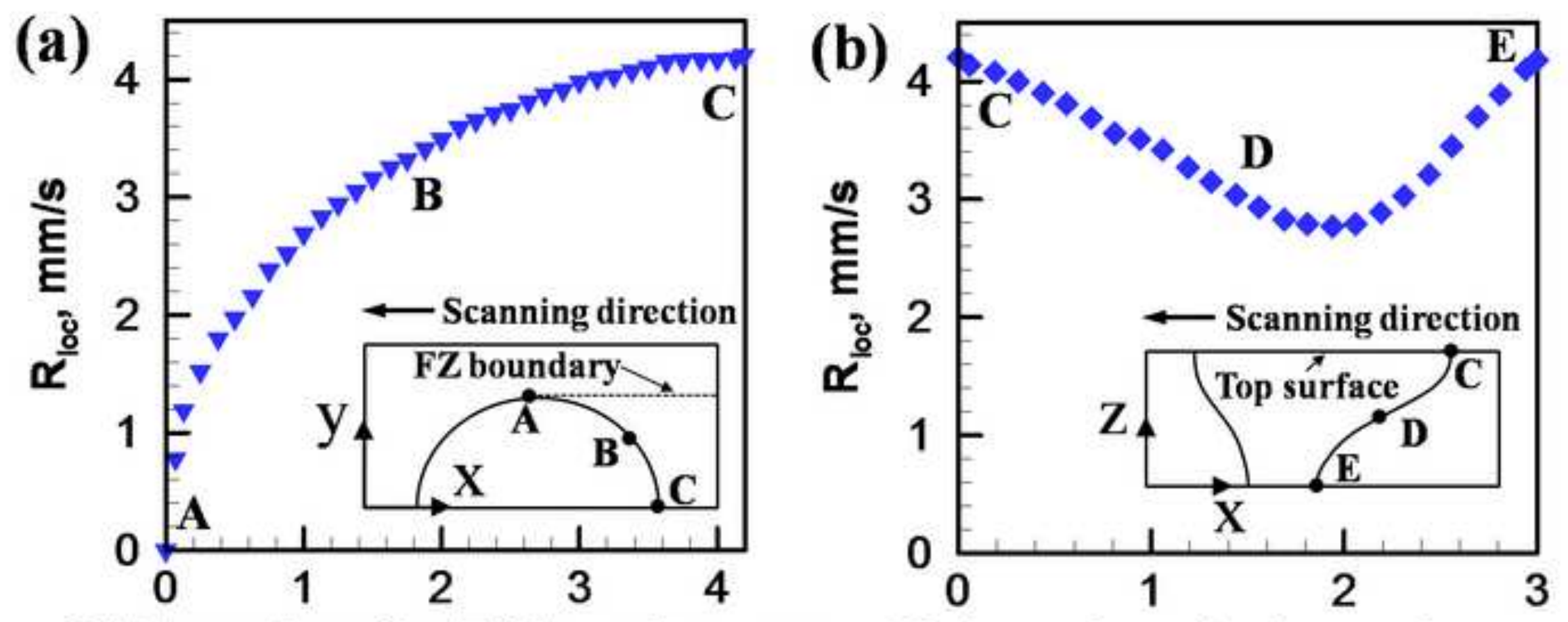

Distance from the $\mathrm{FZ}$ boundary, $\mathrm{mm}$ Distance from the top surface, $\mathrm{mm}$ 
Site selection probability

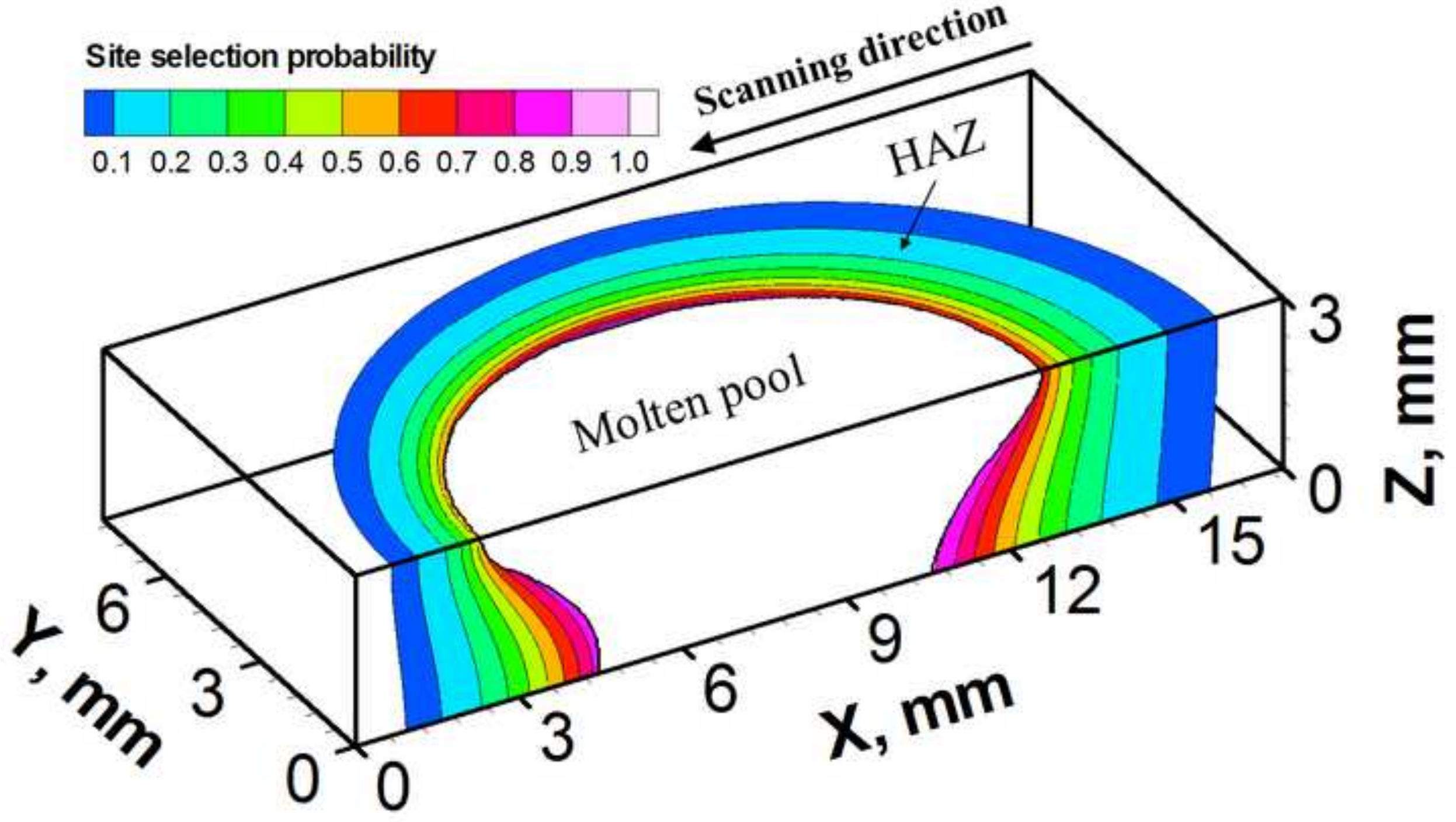




\section{$0.5 \mathrm{~s}$}

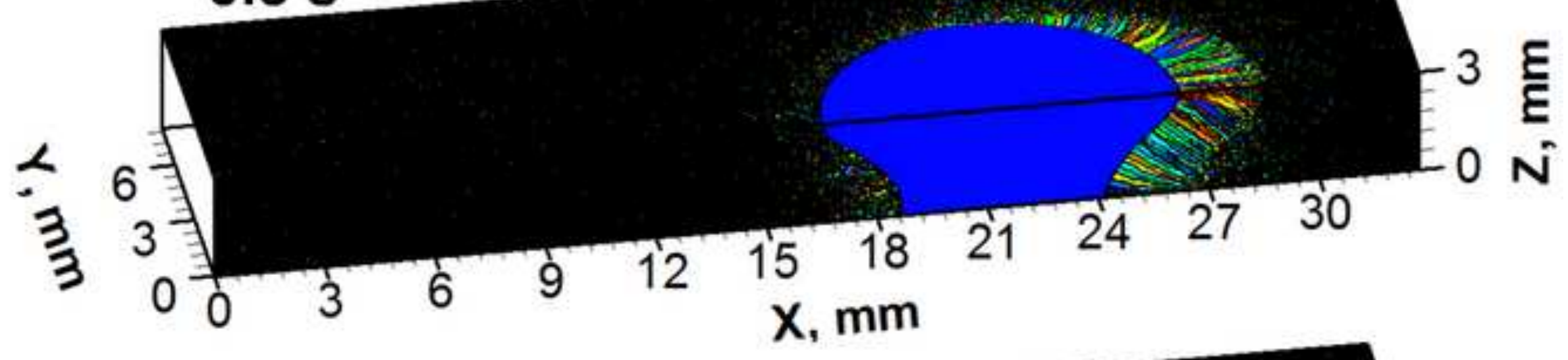

$2.0 \mathrm{~s}$

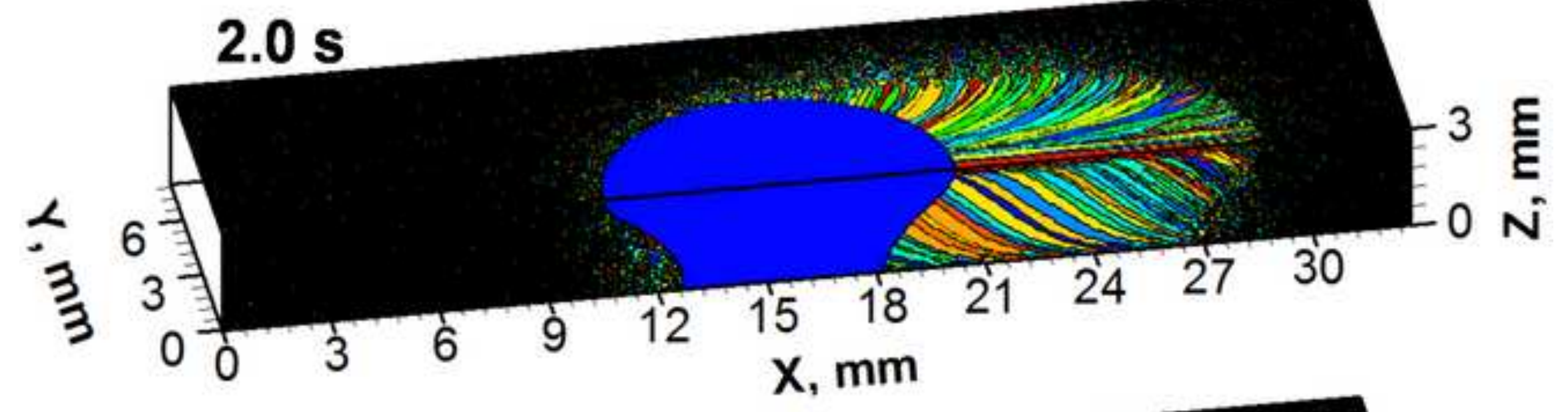
$4.0 \mathrm{~s}$

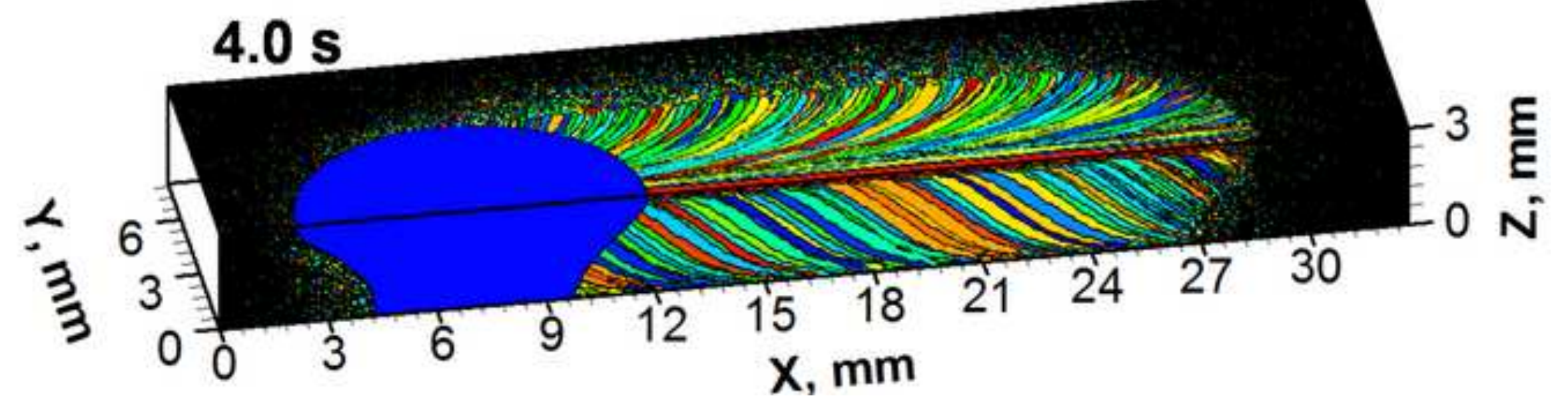



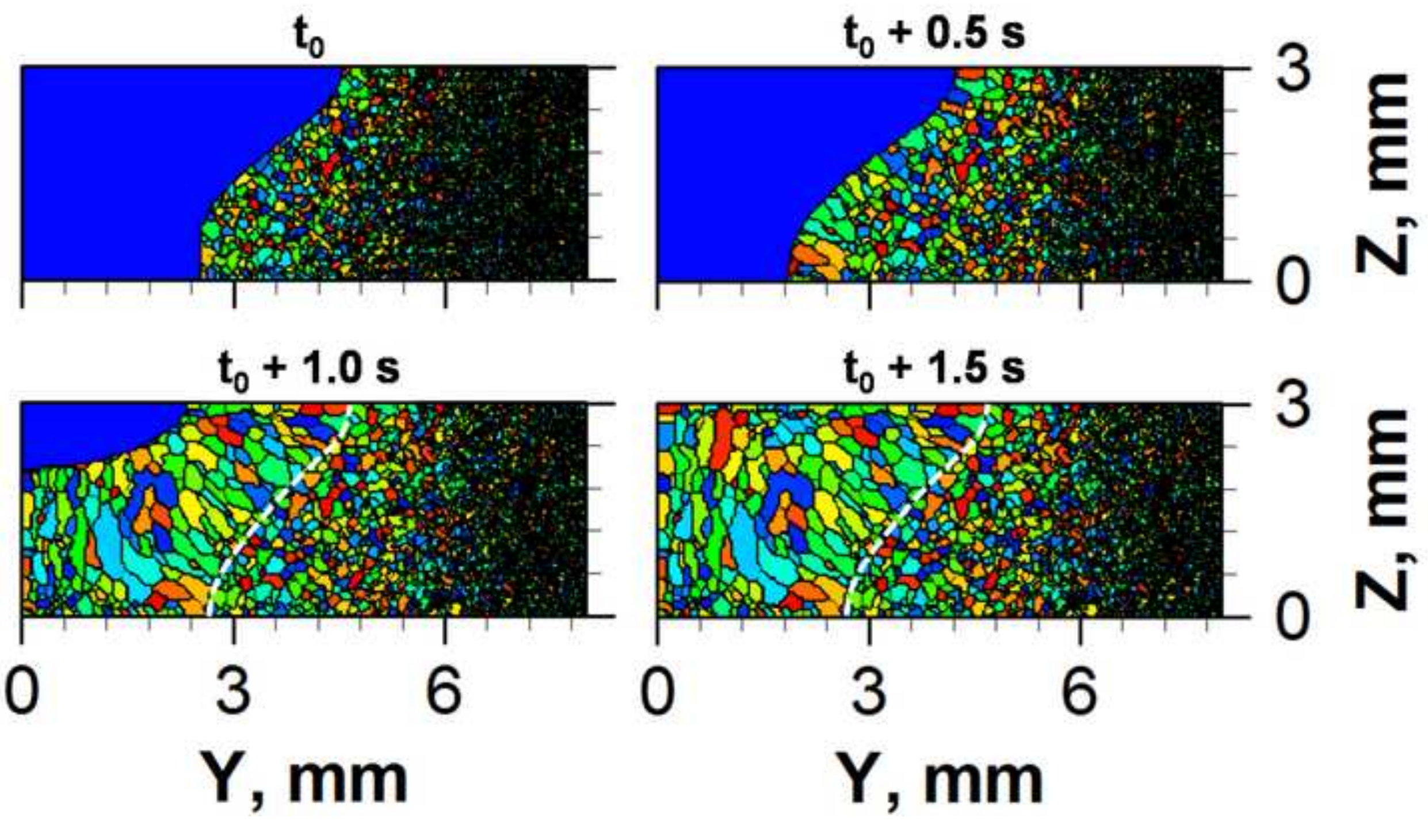

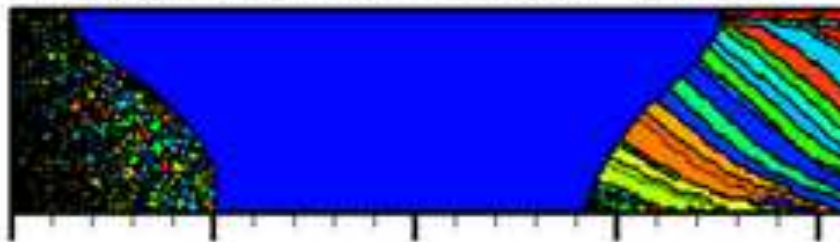

$-2-12$

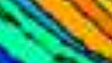

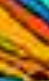

14 N 1 .

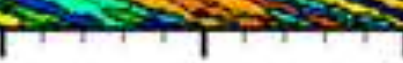

tistis

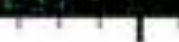

$1.3 \mathrm{~mm}$ from longitudinal central plane
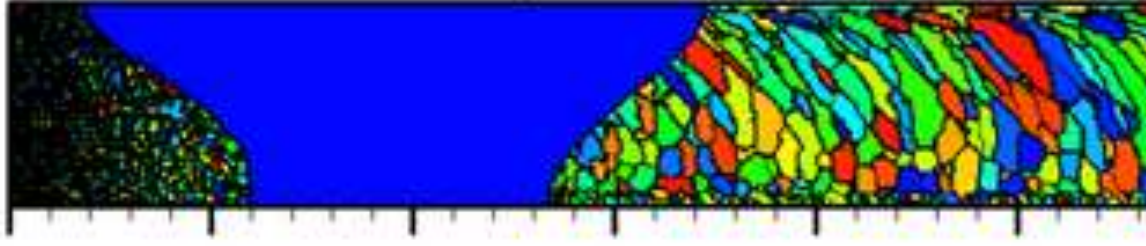

$2.7 \mathrm{~mm}$ from longitudinal central plane
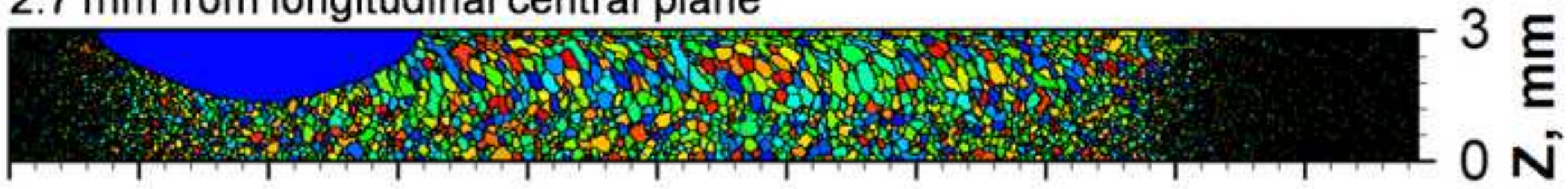

$4.0 \mathrm{~mm}$ from longitudinal central plane

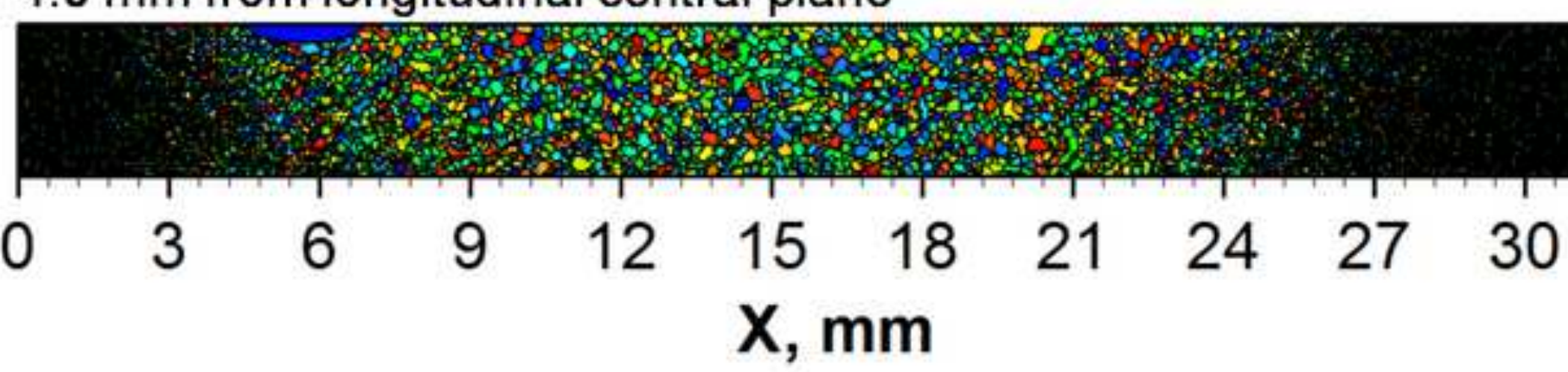

3 ह

$0 \mathrm{~N}$

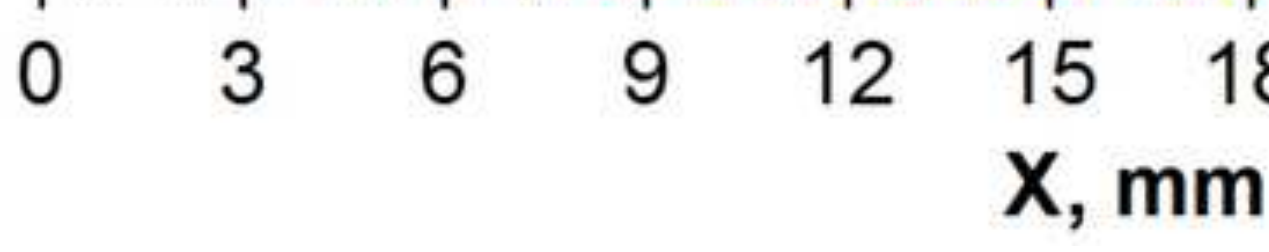




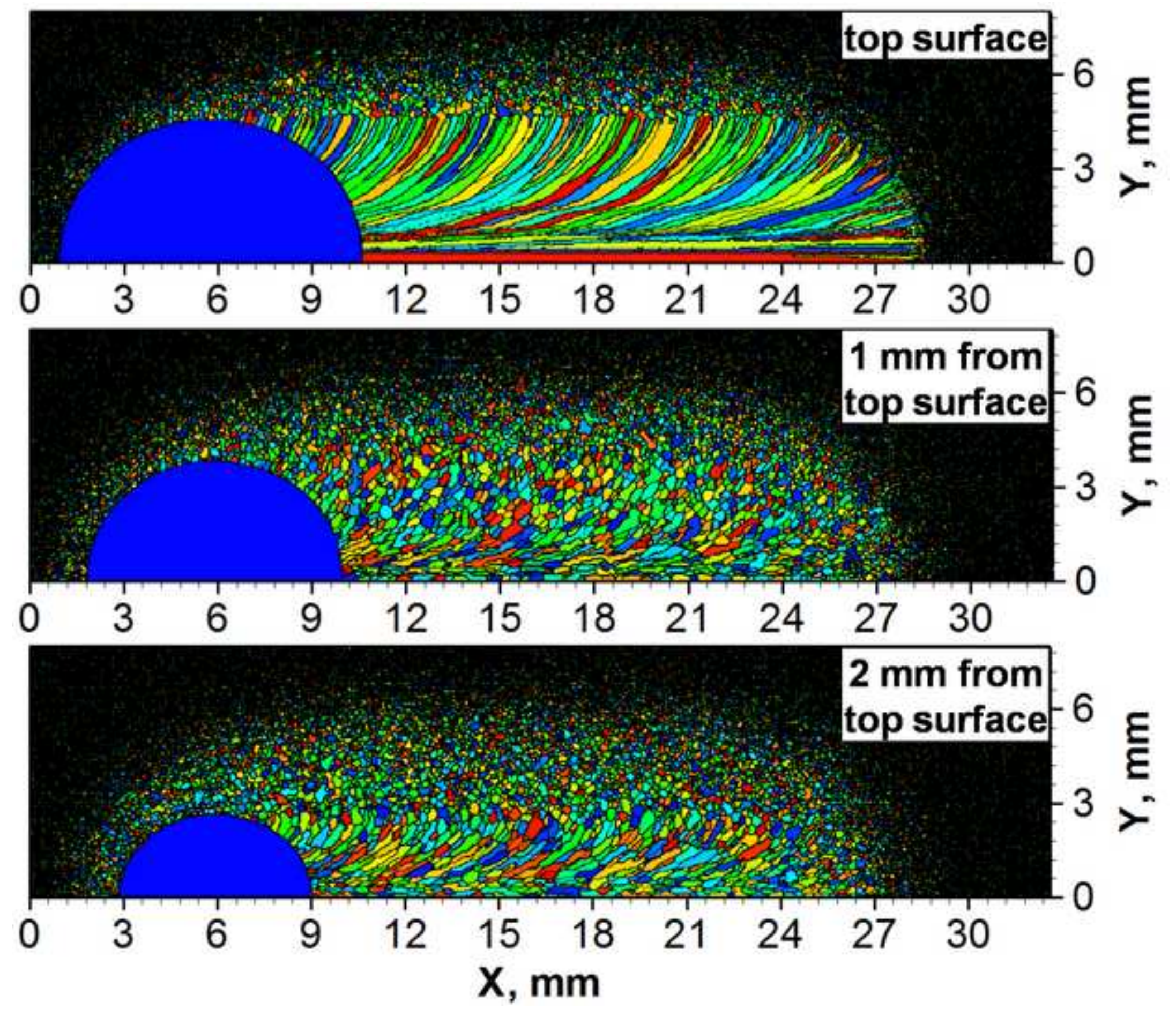




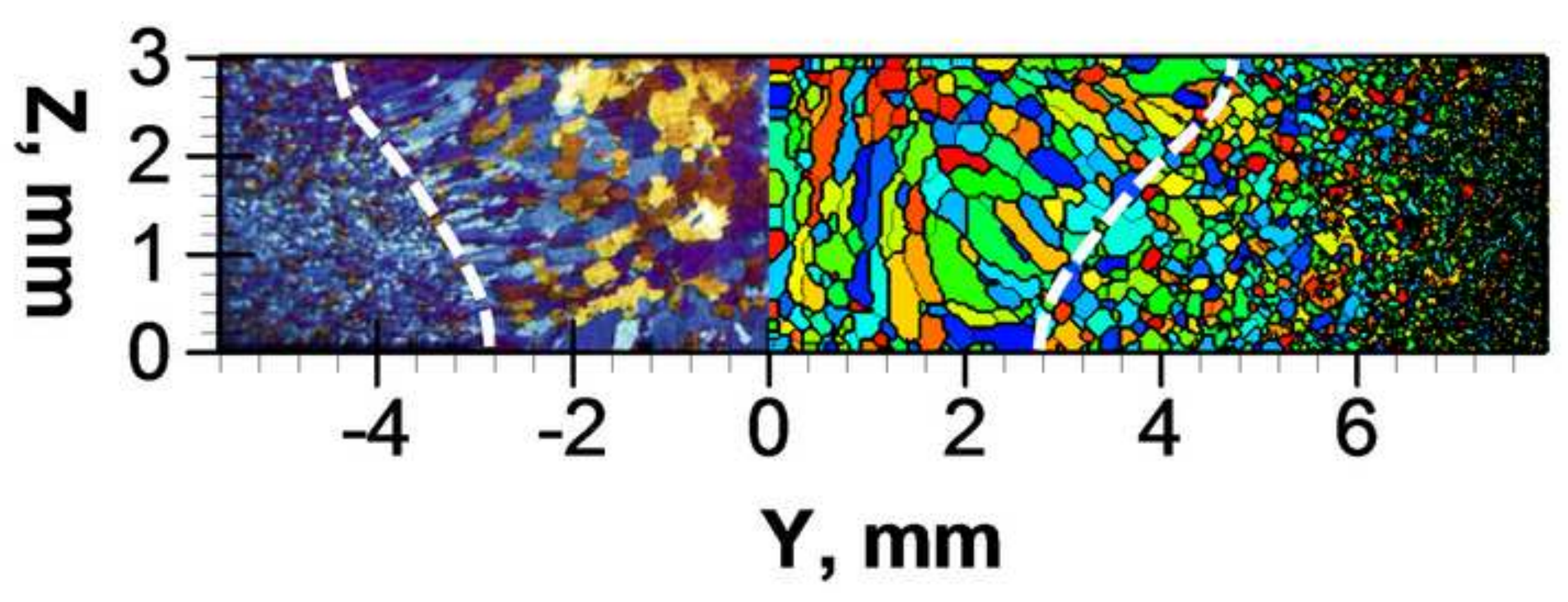




\section{$1 \mathrm{~mm} / \mathrm{s}$}
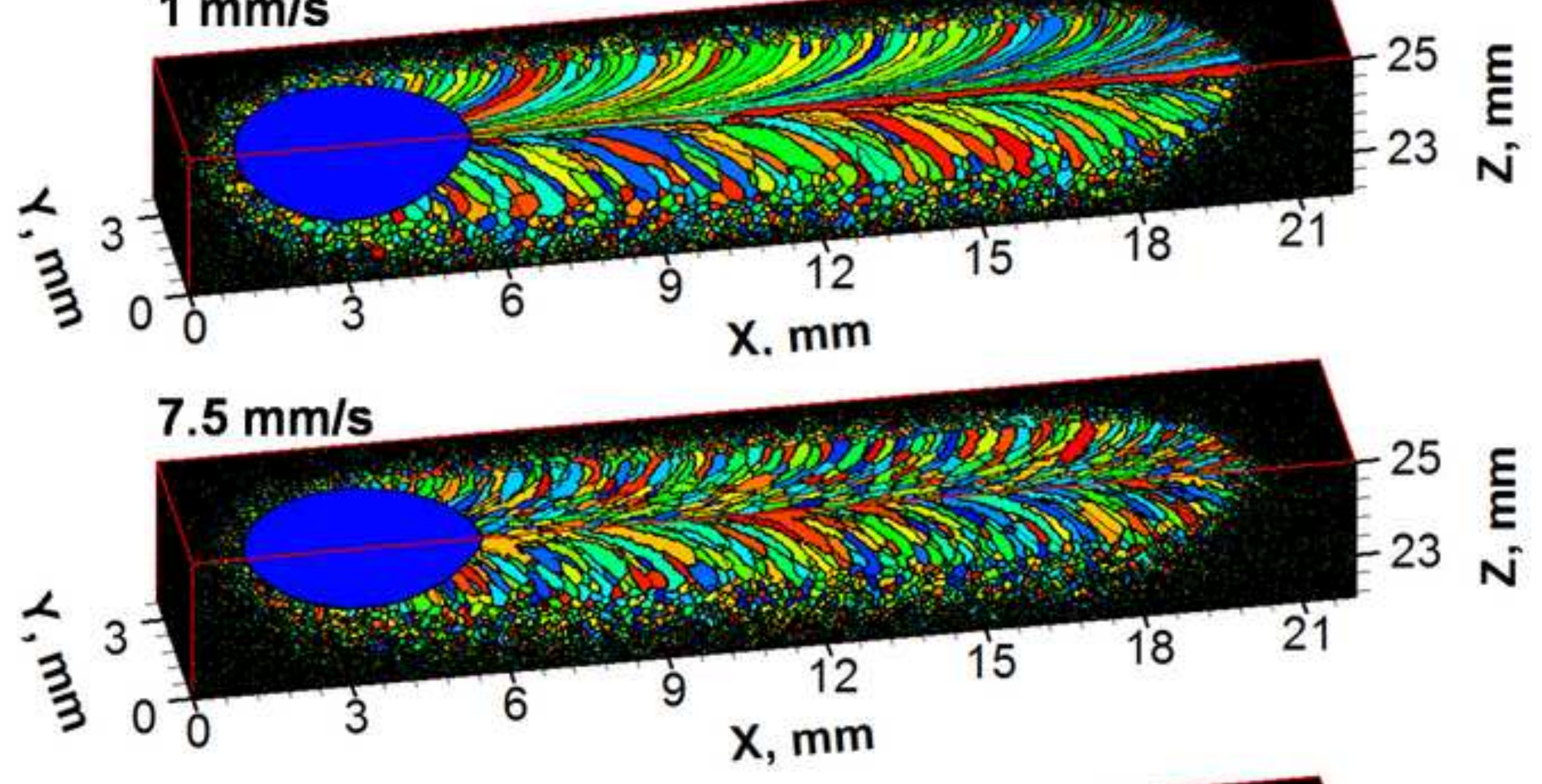

\section{$15 \mathrm{~mm} / \mathrm{s}$}

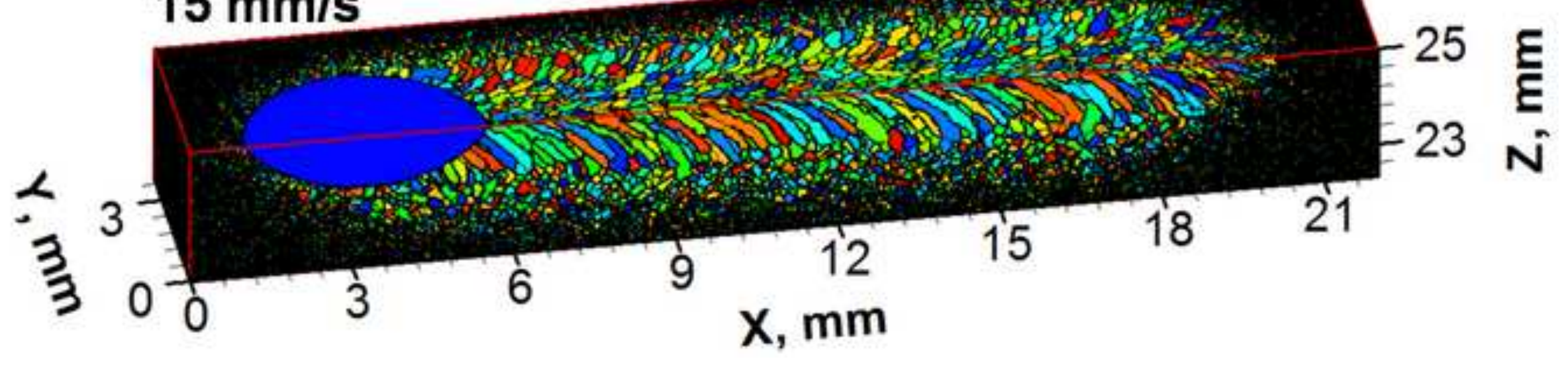



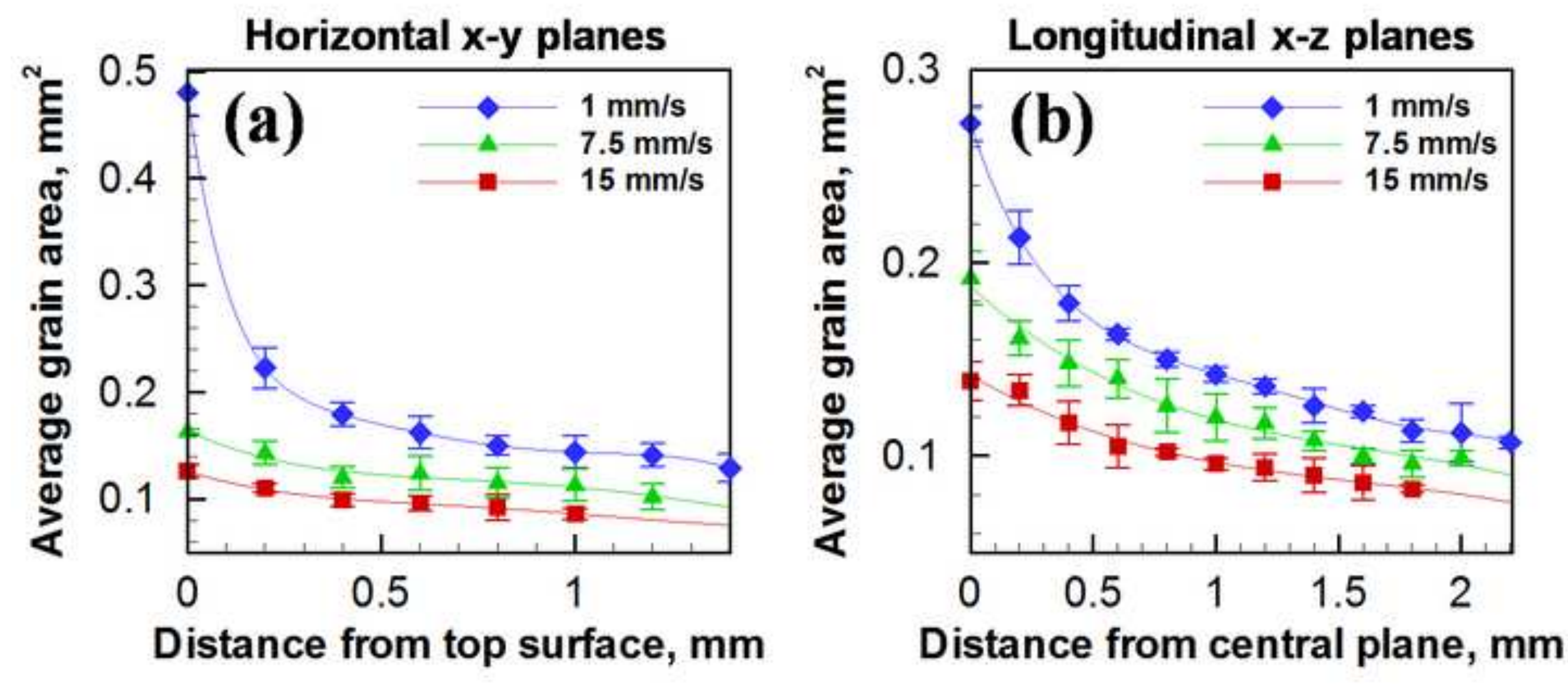

Distance from central plane, $\mathrm{mm}$ 

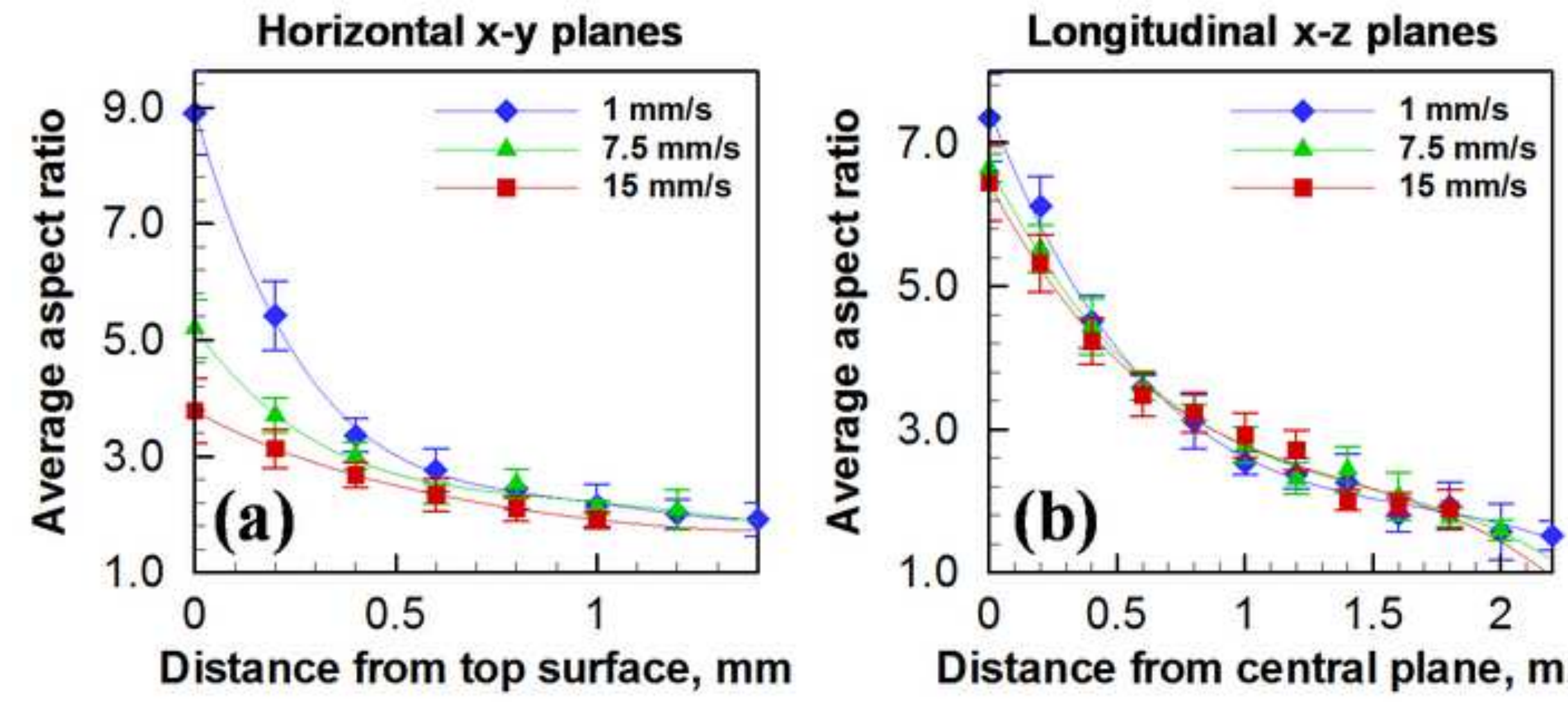

Distance from central plane, $\mathrm{mm}$

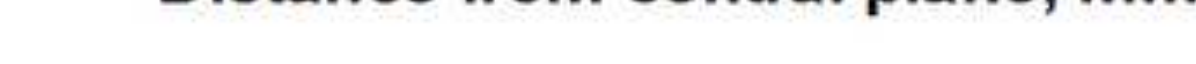




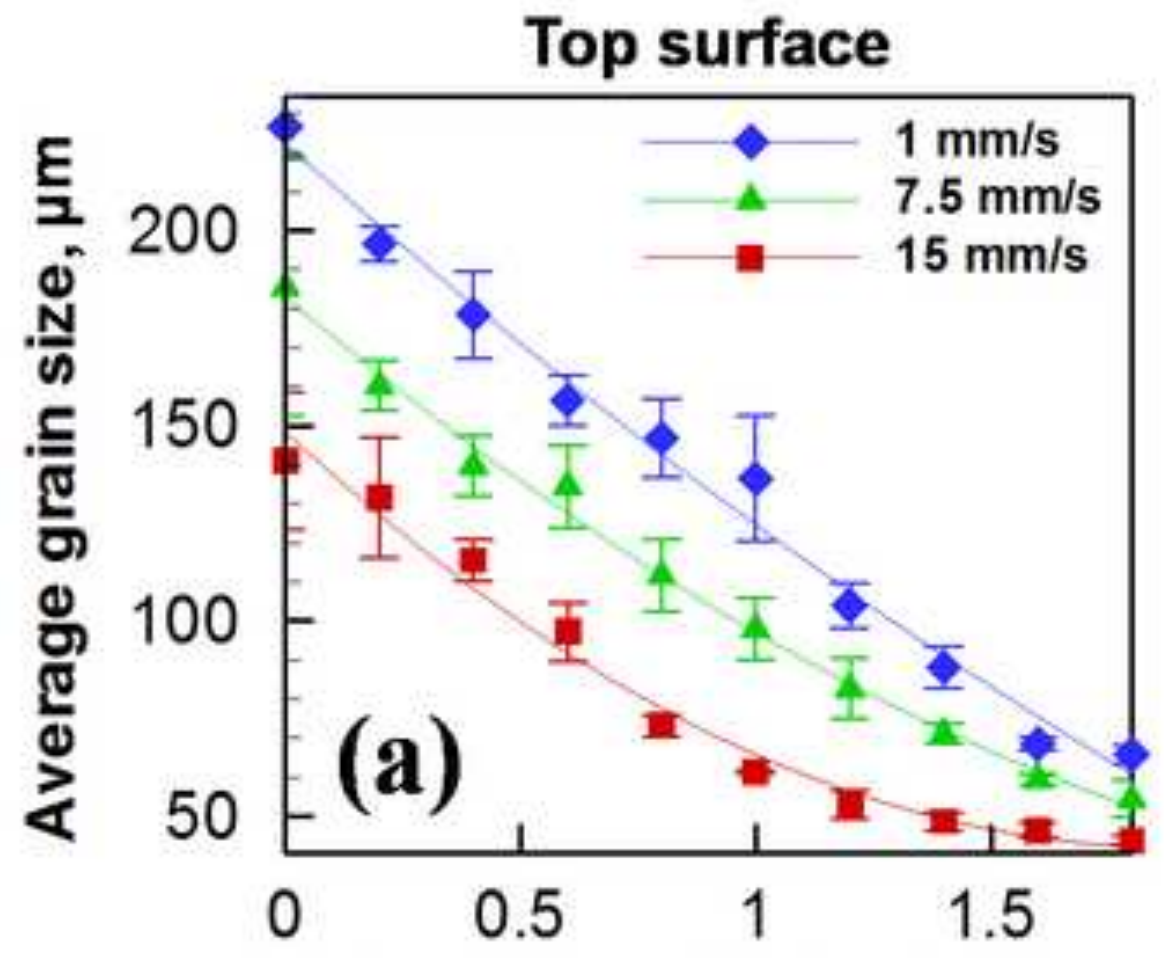

Distance from fusion line, $\mathrm{mm}$

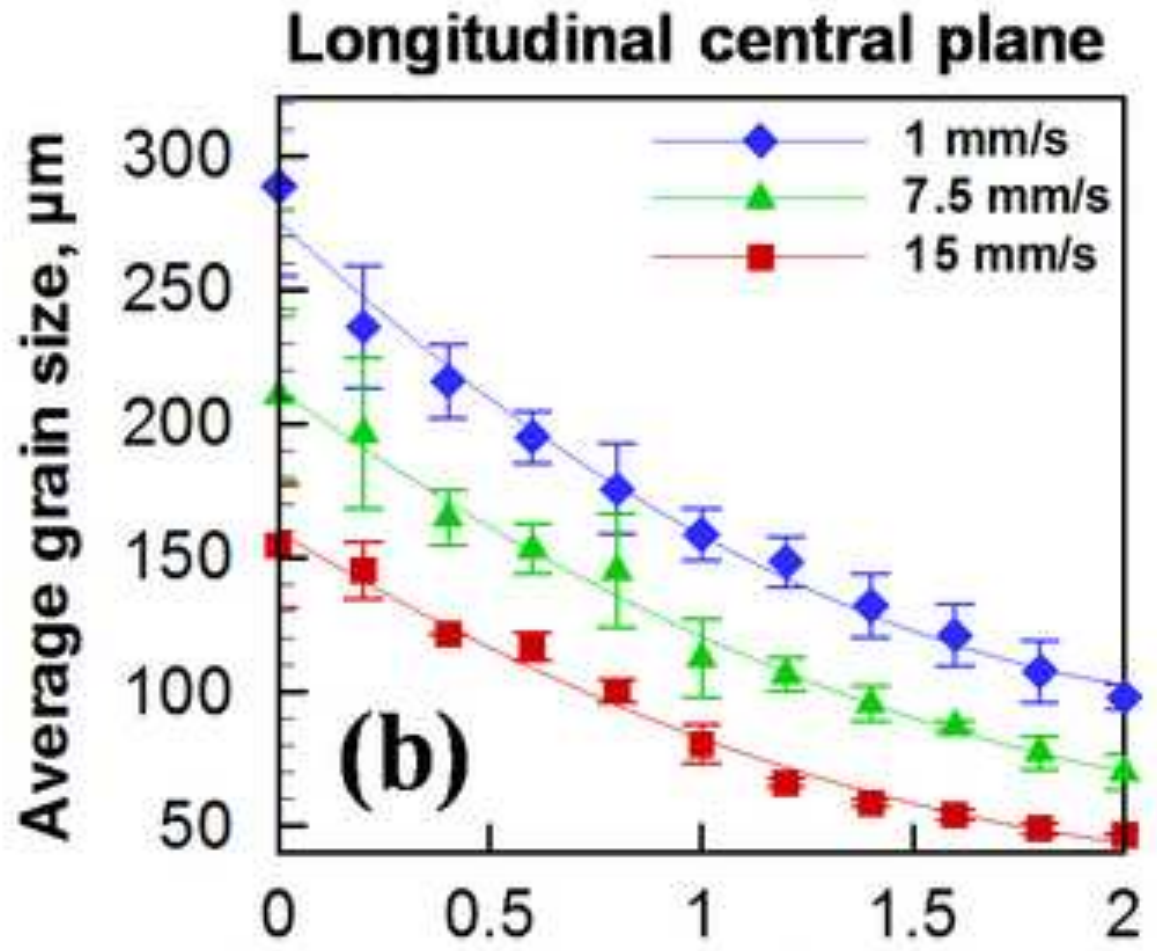

Distance from fusion line, $\mathrm{mm}$ 


\section{Top surface}

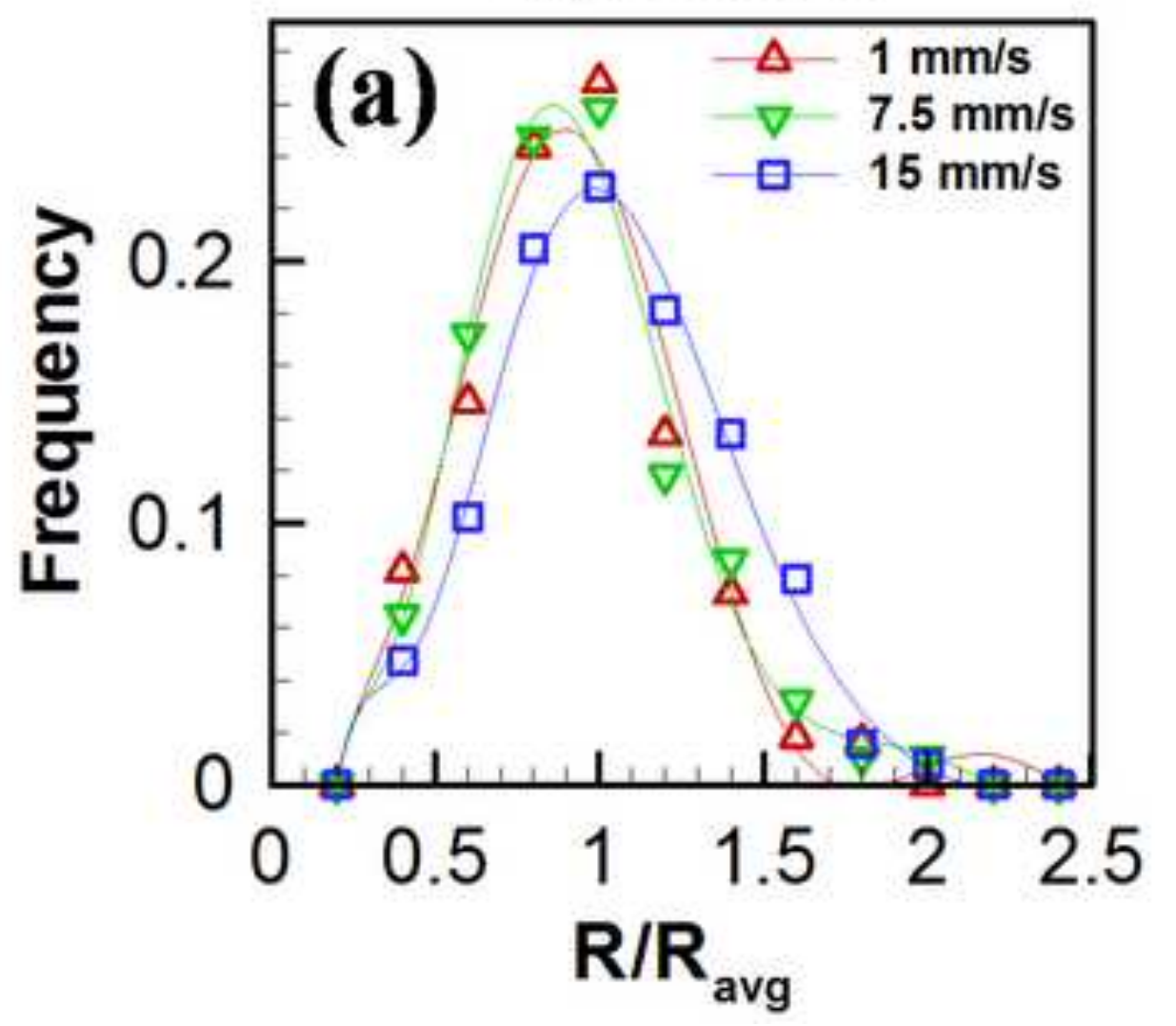

\section{Longitudinal central plane}

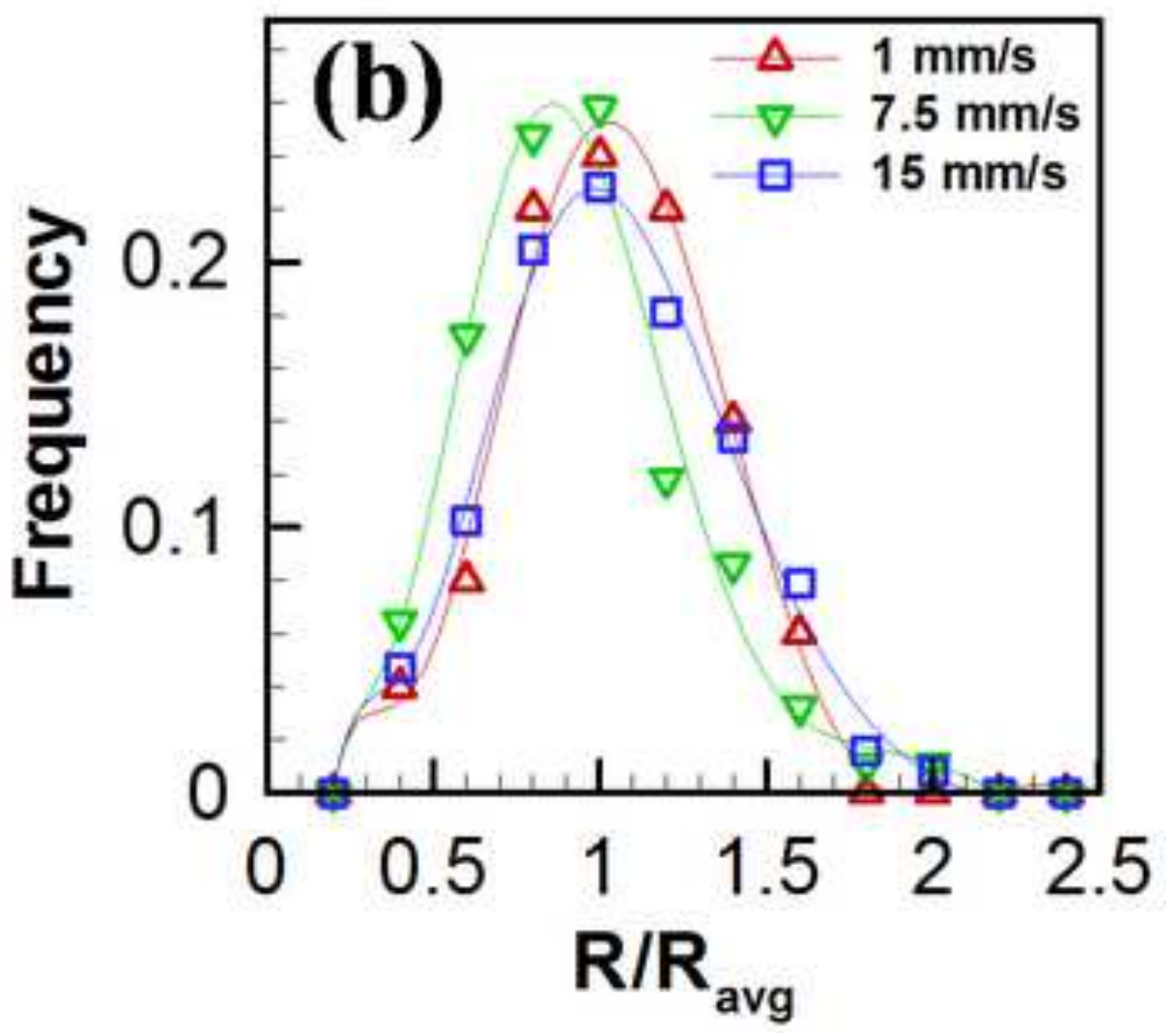



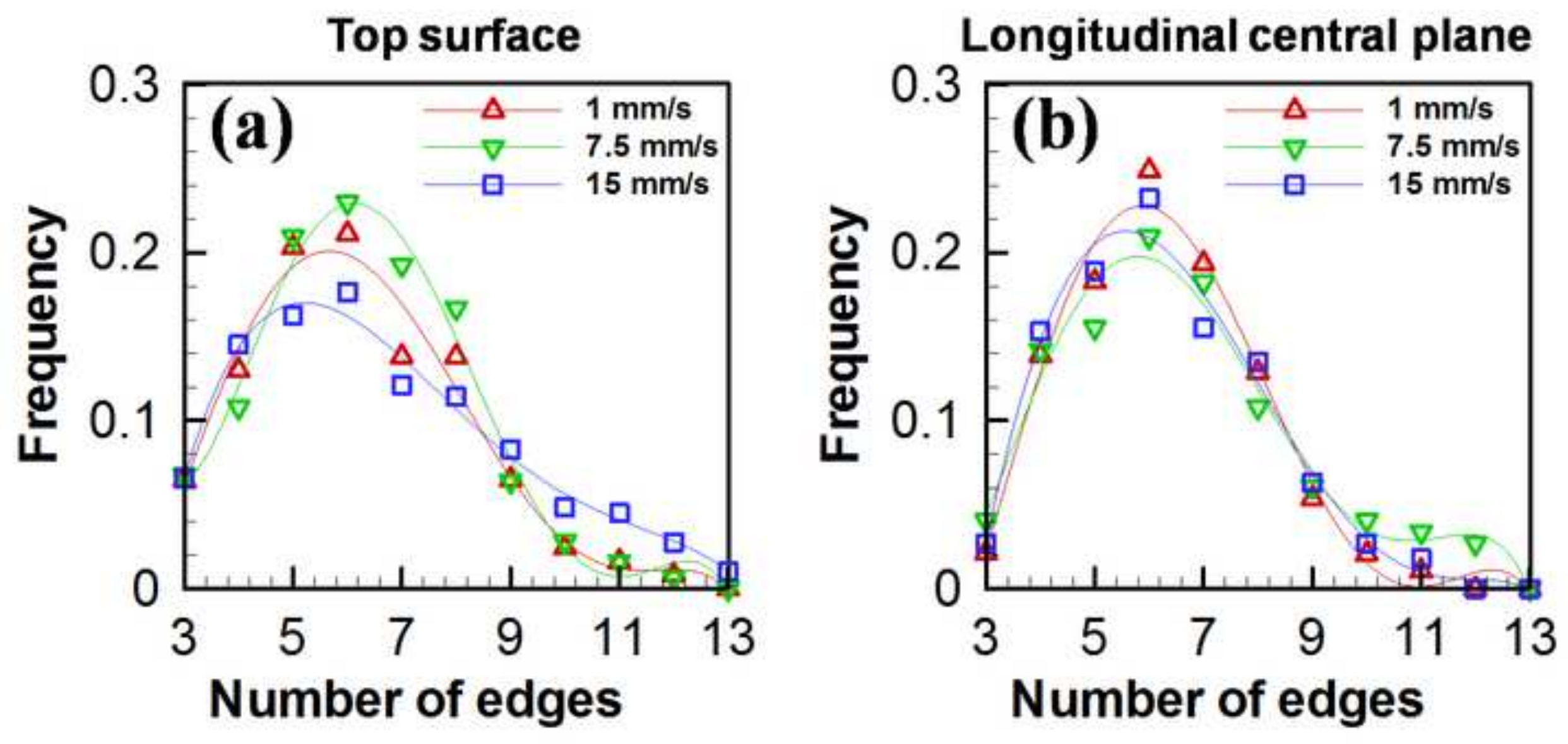


\section{$1 \mathrm{~mm} / \mathrm{s}$}

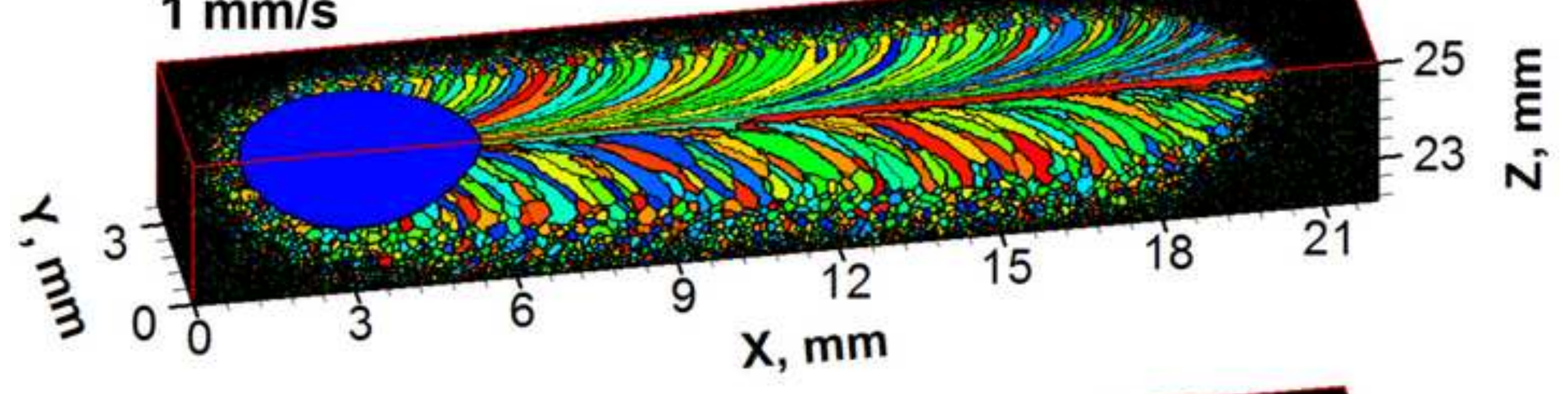

\section{$15 \mathrm{~mm} / \mathrm{s}$}

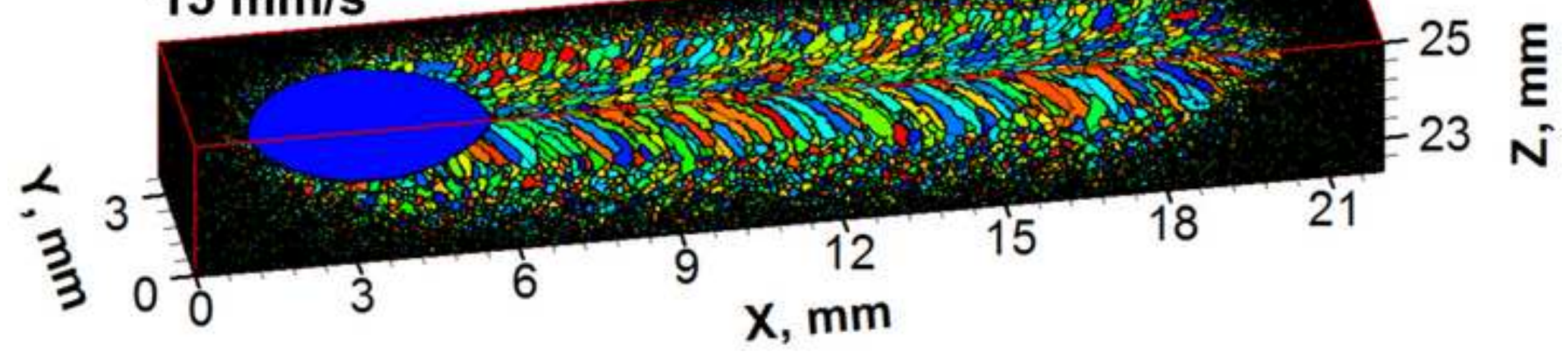

